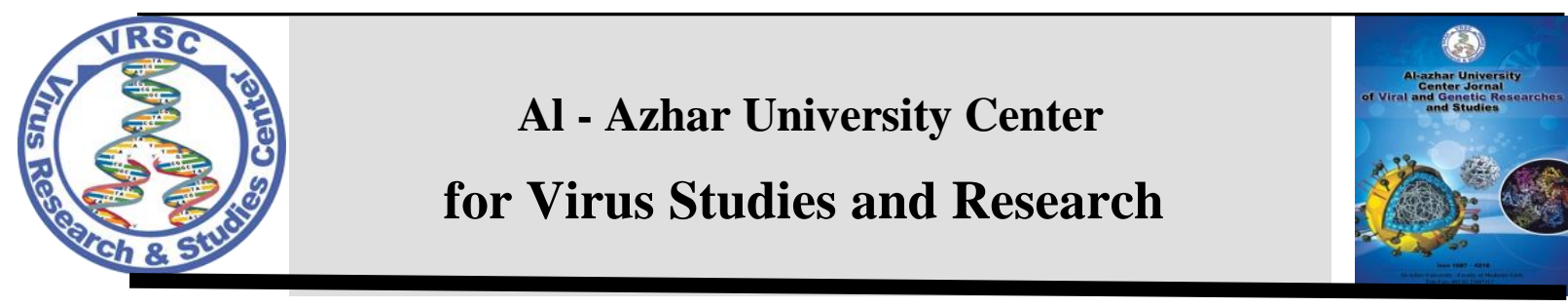

\title{
Grafts in Rhinoplasty
}

\author{
Mohamed Rashad Abdel-Hady ${ }^{1}$, Olfat Abdel-Aziz Sayed ${ }^{2}$ \\ and Khaled Mohamed Ahmed Abdel-Rahman ${ }^{3}$
}

\begin{abstract}
drabdlhady@gmail.com,drolfatsayed@gmail.com anddrkhaledar@gmail.com
1. Prof. of Otolaryngology, Faculty of medicine, Al-Azhar University.

2. Ass.Prof. of Otolaryngology, Faculty of medicine, Al- Azhar University.

${ }^{3}$ Specialist of otolaryngology, Helwan University Hospital.
\end{abstract}

\begin{abstract}
Old rhinoplasty practice has been often relied on resection of the nasal framework in order to achieve aesthetic and/ or functional objectives. Nowadays, careful dissection, conservative resection, planned framework remodeling, \& judicious use of properly selected grafts for augmentation comprise the basis for a structural approach to grafting in rhinoplasty. Aim of the work is to present and evaluate outcomes of using grafts in rhinoplasty. Grafts types, techniques were reviewed. Complications, if encountered, were mentioned. Patient satisfaction was evaluated. Methodology is a prospective study utilized the open rhinoplasty technique, upon 35 patients that suffered from various nasal deformities. Their ages ranged between 18 and 45 years. The followed principles consisted of: 1) A precise definition of the type and cause of abnormality. 2) Definition of the goals. 3) Adequate exposure. 4) Preservation or restoration of normal anatomy 5) Incremental and planned correction. 6) Maintenance of nasal airway. Results are 35 patients operated by the open technique, 23 were males while 12 were females. Of them, 32 cases were fully corrected while, 3 cases were partially corrected. Complications were minimal, occurred in 3 cases. The majority of cases ( 32 cases) were satisfied while 3 cases were unsatisfied. Conclusion is development of sophisticated grafting techniques has played an integral role in achieving durable aesthetic and functional surgical outcomes in rhinoplasty.
\end{abstract}

Keywords

Rhinoplasty, Grafts, Augmentation, Techniques. 


\section{INTRODUCTION}

In History, the earliest known record of surgery to the nose was Egyptian. At that time, Egypt had a highly developed culture in art, literature and science, the glory of which was medicine (Masters and Manchester, 1973). The Edwin Smith papyrus from ancient Egypt outlines the diagnosis and treatment of nasal deformities 3000 years ago (Garrison, 1917). In 1898, Jacques Joseph, a German orthopedic surgeon presented his revolutionary concepts of nasal surgery to the Medical Society of Berlin. He is considered by many rhinoplasty surgeons as the father of modern rhinoplasty (McDowell, 1952). Old rhinoplasty practice has been often relied on resection of the nasal framework in order to achieve aesthetic and/ or functional objectives. The resulted loss of structural integrity would often lead to poor durability of aesthetic outcomes and progressive functional impairment. This has called the need for the development of grafting approaches in modern rhinoplasty. Nowadays, careful dissection, conservative resection, planned framework remodeling \& judicious use of properly selected grafts for comprise the basis for a structural approach to grafting in rhinoplasty. Grafts are used to reconstitute compromised supportive elements and to rebuild nasal framework in case of structural deficiency in order to effect the desired change.

\section{PATIENTS AND METHODS}

This is a prospective study conducted upon 35 patients that suffered from various nasal deformities, from April 2013 to January 2016. Their ages ranged between 18 and 45 years (Mean age 32 years).

Cases included in the study: cases operated by the open rhinoplasty with grafting technique. The Main deformities included were: saddle nose, crocked nose, flaring base, retracted ala and tip ptosis. Cases excluded from the study: cases younger than 18 or older than 45 , if grafts no applicable, cases operated with the closed rhinoplasty technique, cases with psychic problem or cases generally unfit for surgery.

25 patients $(71.4 \%)$ were operated in AL-ZAHRAA Hospital, while 10 patients $(28.6 \%)$ in a private hospital. 30 patients $(85.7 \%)$ were Egyptians while 5 patients (14.3\%) were from other Arab countries. 24 patients $(68.57 \%)$ were males and 11patients $(31.42 \%)$ were females.

The principles that were followed in the work consisted of: 1) A precise definition of the abnormality present and the cause of these abnormalities, as far as can be ascertained from preoperative examination.2) Definition of the goals to be achieved. 3) Adequate exposure of the deformity. 4) Preservation or restoration of normal anatomy 5) Incremental and planned correction of the specific abnormalities identified. 6) Maintenance of the nasal airway.

\section{History taking}

The patients were admitted, a detailed and thorough nasal history was obtained. A discussion about patient motivations was carried out. Specific questions regarding previous trauma, previous nasal or sinus surgery, nasal allergy, tobacco, and drug use provide important information regarding nasal function. A list of current and past medications for treatment of allergies and nasal or sinus problems were obtained.

\section{Physical Examination}

Thorough clinical examination is done to all a cases including:

A-External examination: 1-Inspection of the nose begins with observation of the patient during quiet respiration. Note whether the patient is breathing through the mouth or nose, document collapse of the lateral nasal sidewalls if present. The sebaceous gland concentration in the nasal skin is also noted, as are any scars or other asymmetries. The nasal valve is then observed during sniffing. The external 
and internal nasal valves are then examined and evaluated. External valve collapse may be noted in thin-skinned individuals with narrow nostrils. Collapse of the internal nasal valve is a much more common cause. The role of the depressor nasi septi muscle is evaluated by examining the tip during animation on both frontal and profile views.

2-Palpation: Bony and cartilaginous irregularities are identified. The thickness of the skin is verified. Gentle ballottement of nasal tip gives information regarding its structural integrity and support.

Ballottement (tip recoil test) of the nasal tip gives information regarding tip support.

Bidigital manipulation of the caudal septum and its relationship to the medial crura can be obtained by gently grasping and rotating the columella.

\section{B-Internal nasal examination 1-Nondecongested} examination: A speculum examination of the nasal cavity and assessing the nasal airway is important. The internal nasal valve is formed by the caudal edge of the upper lateral cartilage, septum, and the floor of the nose. This area is the single greatest contributor to airway resistance and is examined in every rhinoplasty candidate.

If a cause of nasal obstruction is not found anteriorly, a fiberoptic examination of the nasopharynx should be performed.

Assessing for the presence or absence of septal cartilage is also wise. This is especially important in cases of revision rhinoplasty in which septal cartilage may have been previously harvested. Lack of enough septal cartilage may prompt the surgeon to harvest cartilage from other sources.

\section{2-Specific tests:}

Superior tip rotation test: Nasal tip ptosis is a common cause of airway obstruction, especially in the older patient. Superior rotation of the tip with a finger while the patient inspires is a helpful maneuver that aids in the diagnosis of this problem. If positive, maneuvers to superiorly rotate and stabilize the nasal tip should be used.
The Cottle maneuver is performed in all patients with nasal airflow obstruction. This is performed by pulling the midfacial soft tissue laterally at the

melolabial folds. Improvement in nasal airflow is diagnostic for internal nasal valve collapse.

$\boldsymbol{A}$ modified Cottle maneuver may be performed using a cerumen loop to manually lateralize the upper lateral cartilages endonasally. Improvement in nasal airflow during this maneuver is helpful in predicting the success of nasal valve surgery.

3-Decongestant examination: topical phenylephrine was applied using an atomizer. The inferior turbinate was examined and compared with the nondecongested state. Any new septal deflections, septal spurs, or deviations of the perpendicular plate of the ethmoid was noted. The internal and external nasal valves were again examined in the manner outlined above.

\section{Photography and Analysis}

Photography (frontal, basal, lateral, and oblique views) followed by nasofacial analysis were performed systematically in every patient to evaluate for the possible presence of facial anomalies and to determine the nasal deformity. The following guide was applied for analysis:

Frontal View:Twisted or straight: Follow brow-tip aesthetic lines. Width: Narrow, wide, normal, "wide-narrow-wide".Tip: Deviated, bulbous, boxy, asymmetric, amorphous, other.

Basal View:Triangularity: Good versus trapezoidal. Tip: Deviated, wide, bulbous, bifid, asymmetric. Base: Wide, narrow, or normal. Inspect for caudal septal deviation. Columella: Colurnellar/lobule ratio (normal is 2:1 ratio); status of medial crural footplates.

Lateral View: Nasofrontal angle: Shallow or deep Nasal starting point: High or low. Dorsun: Straight, concavity, or convexity, bony, bony cartilaginous, or cartilaginous (i.e., convexity primarily bony, cartilaginous, or both).Nasal length: Normal, short, long.Tip projection: Normal, 
decreased, or increased. Alar-columellar relationship: Normal or abnormal.Naso-labial angle: $\quad$ Obtuse or acute.

\section{Preoperative Investigations}

Routine preoperative investigations like CBC, Fasting and Postprandial blood sugar, Liver function tests, Kidney function tests, Bleeding profile, CT nose and paranasal sinuses both coronal and axial cuts were carried out. A general assessment of fitness for general anaesthesia was carried out by anesthetist. AT last, the operation was explained to every patient and his/her and our expectations from the operation were discussed. A written consent was signed out.

\section{Operative technique}

\section{a- Basic operative steps followed in most cases} were:

1) Anesthesia: general with oral endotracheal intubation. 2) Position: Patient supine in the beach chair position. 3) Septoplasty: was done to correct septal deviation and/or to harvest septal cartilage graft material.

4) Inverted V-shaped transcolumellar incision that was connected bilatellyra with a marginal incision. 5) Dissection of skin soft tissue envelope (S-STE) out of bony/cartilaginous nasal framework by sharp and blunt dissection in the SubMuscloAponeurotic space (SMAS).

6) Performance of augmentation and/ or reduction technique according to the need. 7) Osteotomies
Oblique View: Does it add anything, or confirm the other views?

done whenever indicated.8) Closure of septal incision with interrupted 4-0 vicryl sutures. 9) Suturing of mucoperichondrial septal flaps by figure of (8) 4-0 vicryl sutures.10) Closure of marginal incisions with interrupted 4-0 vicryl sutures.11) Closure of transcolumellar incision by 6-0 prolene sutures. 12) Application of anterior nasal pack (only if bleeding was encountered).13) Application of sterristripe.14) Application of external nasal splint (if osteotomies were done).

\section{b- septoplasty and septal cartilage graft harvest:}

1) Incision in the wide nasal side (killian, modified killian, hehitransfixion or complete transfixion). Sometimes, if total septal reconstruction was indicated the septum was accessed via separation of the upper lateral cartilages (ULC) from the dorsal septum and lateralization of the lower lateral cartilage (LLC) to expose the anterior septal angle (Dorsal Approach). 2) Dissection and elevation of the mucoperichondrial/mucoperiosteal flaps bilaterally.3) Excision of enough part of septal cartilage taking into consideration to preserve adequate L-shaped strut $(1.5 \mathrm{~cm}$. caudally and 1.5 cephalically) to support the dorsum and tip.3) Closure of incision by interrupted 4/0 vicryl. 4) Figure of (8) closure of muchoprichondrial flaps with 4/0 vicryle (Figs. 1 -4).

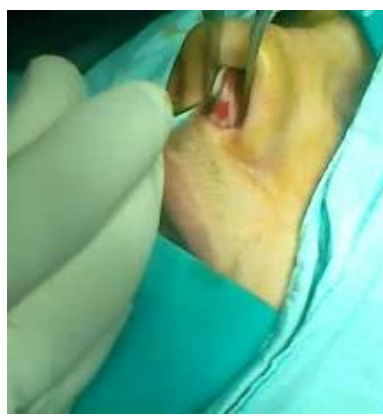

Fig.1: incision

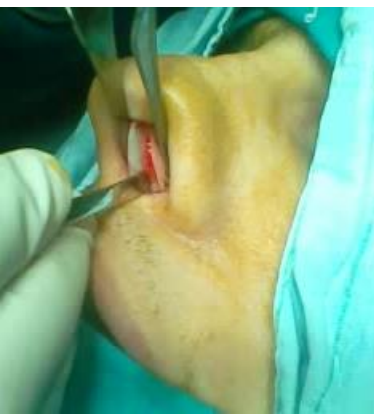

Fig.2: dissection

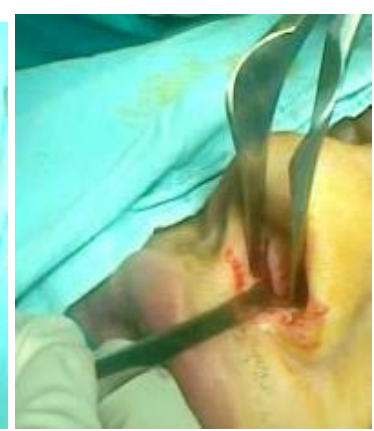

Fig.3: flaps elevation

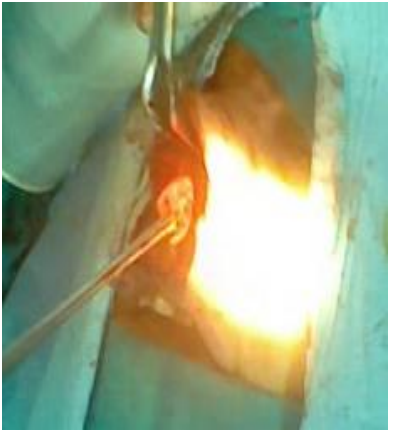

Fig.4: septal graft harvest
c-Conceal cartilage harvest:
Auricular cartilage was harvested using the anterior approach. 1) With a no.15 blade, an incision that 
follows the outer edge of the cavum and cymba concha was made. This incision was placed along the portion of the concha that is vertically oriented in relation to the lateral aspect of the skull. 2) a syringe with saline was used to "hydrodissect" the skin of the concha cavum and cymba from the underlying cartilage. 3) the skin and perichondrium was elevated from the underlying cartilage. Dissection proceeded by using appropriate scissors, and also bluntly with cotton-tip applicators. Care should be taken not to damage the soft auricular cartilage, which can tear. The dissection should stop short of the cartilage of the external auditory canal. The radix helicis should be preserved if preservation of ear position is critical. If the entire

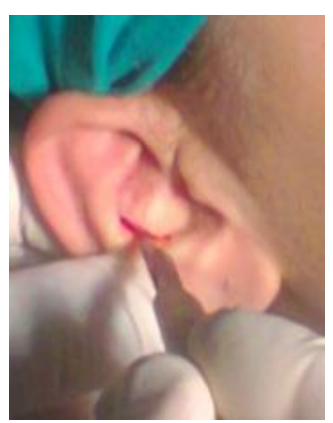

Fig5: incision.

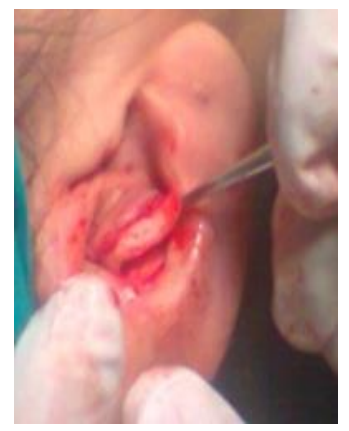

Fig6: dissection and flap elevation.

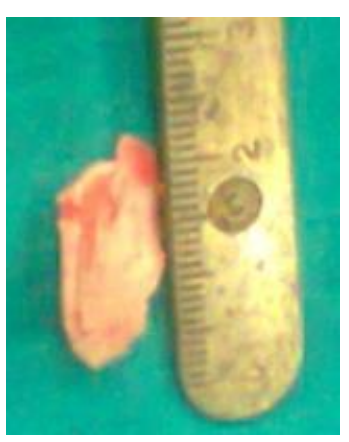

FigFig.7: cartilage. harvest conchal bowl is excised, the auricle will usually settle closer to the head. 4) the desired piece of cartilage was dissected out leaving the underlying muscle behind. (perichondrium will remain adherent to the posterior surface of the cartilage). Avoiding deep dissection into the soft tissue minimizes bleeding. 5) the incision was closed with a 6-0 interrupted vertical mattress prolene sutures. Special care must be taken to avoid overlap of the skin edges. 6) A suitable piece of cotton pack was placed into the concha and sutured into position to decrease the risk of hematoma. 7) the sutures were removed by the $5^{\text {th }}$ day (Figs. 5-9).

\section{d-Tragal cartilage harvest:}

1) A circumferential incision is made in the tragus from the medial aspect sparing the dome to preserve the contour of the tragus. 2) Dissection of perichondrium with scissor and cottonoid tip applicators and elevation from both sides. 3)

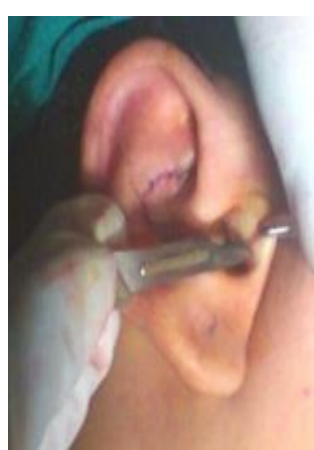

Fig10: incision

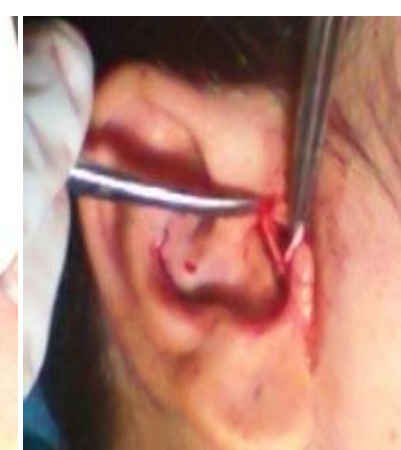

Fig11: dissection
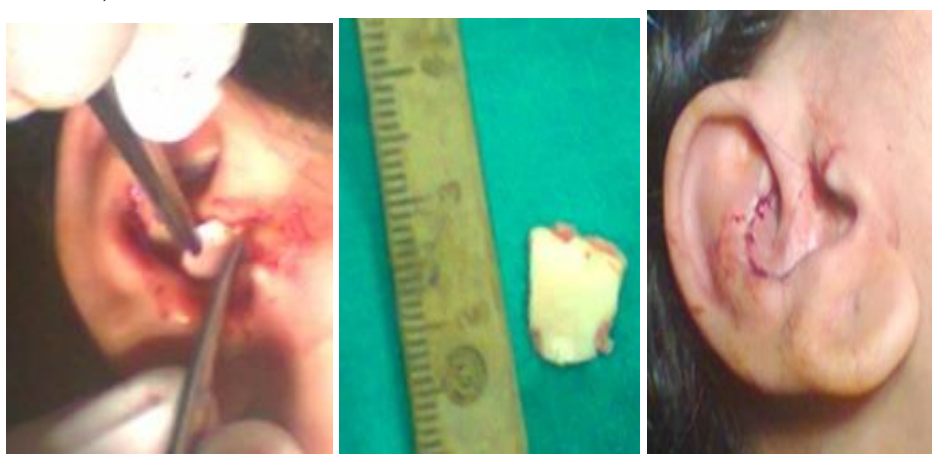

Fig12: excision

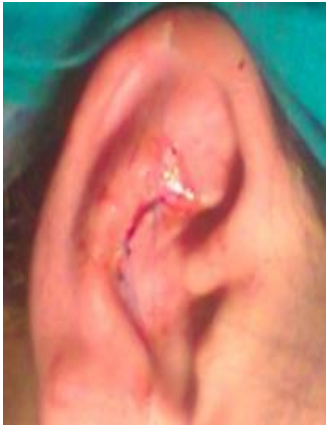
closure
Fig9: suture of

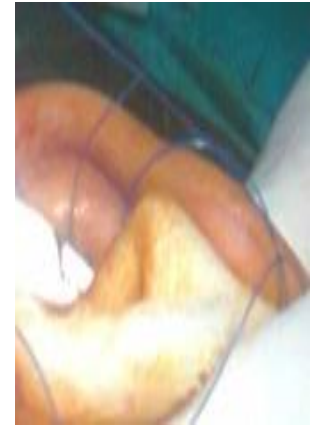

a compression dressing

Excision of the cartilage with scissor. 4) Closure of the wound with 6-0 prolene and application of compression dressing. 5) Sutures removed by the $5^{\text {th }}$ day. (Figs. 10-14).

\section{e-Temporalis fascia harvest:}


Deep temporal fascia (DTF) is used exclusively due to its thickness and long-term survival for primary rhinoplasty cases using only autologous tissues to improve the curve of hump noses and depressions. For secondary rhinoplasty cases, DTF was used to improve implant demarcation and transparency.

Technique: We routinely harvest a $5 \times 5 \mathrm{~cm}$ piece of deep temporal fascia (DTF) through a $3.0 \mathrm{~cm}$ incision above the auricle. A straight line is drawn coming up from the tragus. The hair is not shaved.

2) The area is injected with local anesthesia containing epinephrine. 3) The incision passes downward to the subcutaneous tissue which is spread transversely with the scissors. 4) Haemostasis is checked at this point. 5) The

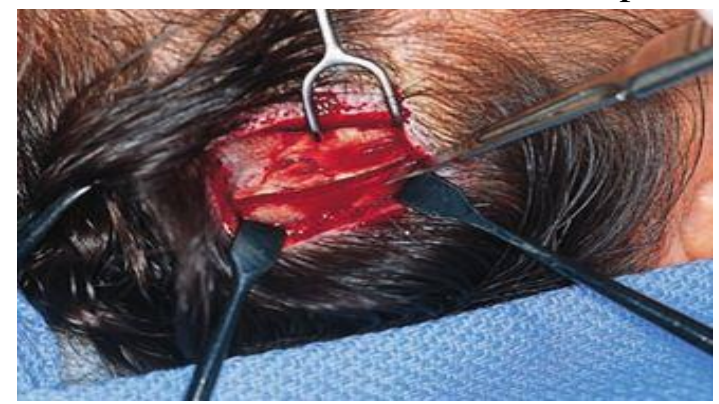

Figure 15: incision, dissection\& flap elevation

\section{Sculpturing of columellar strut:}

Standard Columellar Strut measure approximately $20 \mathrm{~mm}$ in length and $2-3 \mathrm{~mm}$ in width with the thicker portion located inferiorly (Fig. 17). The strut is placed between the lateral crura with the inferior end short of the nasal spine. The crura are then advanced upward and rotated medially $90^{\circ}$ before superficial temporal fascia is penetrated, and the loose areolar layer is found with the gleaming white DTF underneath. 6) Then the scalp is retracted superiorly using two Ragnell retractors. 7) The fascia will be incised as 4 arcs: 1- superiorly at the junction of DTF and perichondrium, 2- anteriorly at its split to accommodate the deep temporal fat pad, 3- inferiorly down to the top of the ear, and 4posteriorly as far back as necessary. 8) As the DTF is incised, one sees the underlying red temporalis muscle. The scalp is then retracted in each of the other three quadrants and the fascia incised. A large fascia graft is removed. 9) Incision closed with 4-0 prolene. (Figs.15and 16).

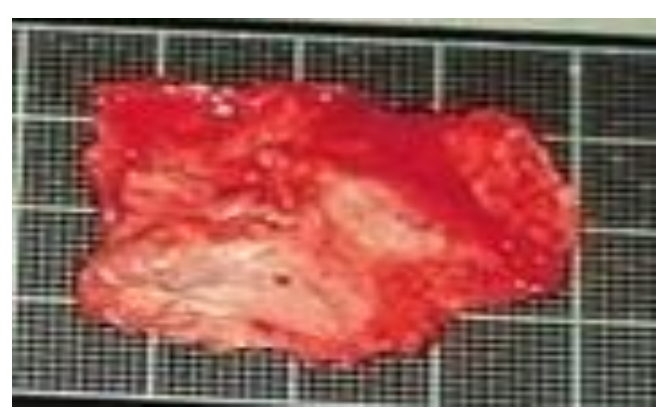

Figure 16: harvested temporalis fascia being fixed to the strut with a \#25 needle just below the domes. A horizontal suture of 5-0 prolene suture fixes the crura to the strut and is placed in the middle crura above the columellar breakpoint. The superior portion of the strut can be cut to fit beneath the domes and the inferior portion cut off, if there is too much fullness in the columellar labial angle.
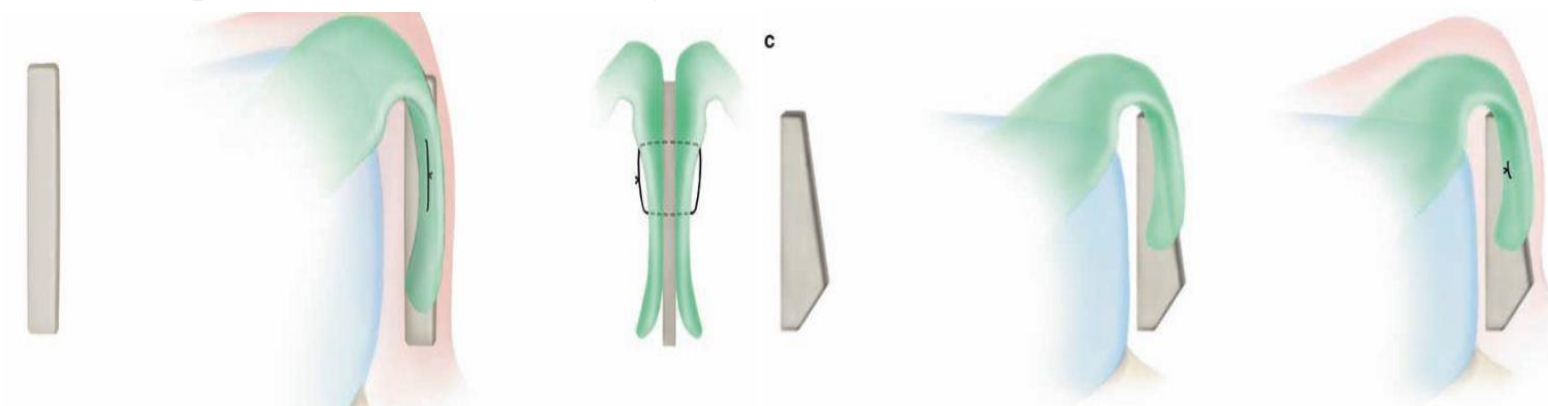

Fig. 17: sculpturing columellar strut Fig.18: sculpturing of columellar strut

Extended Columellar Strut.
These grafts tend to be longer $(30 \mathrm{~mm})$ and shaped to influence the columella labial angle. They 
measure $8-10 \mathrm{~mm}$ at their widest portion which is the junction between the upper two third and the lower one third of the strut. After its insertion between the crura, a distinct change should be seen at the columella labial angle. Again, the graft is kept short of the anterior nasal spine (ANS) to avoid clicking. These grafts are frequently used in ethnic noses and in the older patient with an acute columellar labial angle (Fig.18).

\section{Sculpturing of Shield (sheen) graft:}

It shaped like a shield with dimensions measuring 12-16 mm long, 8-10 $\mathrm{mm}$ wide at the top tapering to $4 \mathrm{~mm}$ inferiorly, and $1-3 \mathrm{~mm}$ thick with greatest thickness superiorly. The goal is to have the superior edge of the graft create the tip definition while the columellar portion blends in with the crura. Prior to suturing the graft in place, two critical steps have been completed: the crural strut has been inserted and the domes have been modified. Before suturing the graft to the stable columella platform, a major decision must be made: integrate the graft into the existing tip configuration or project the graft above the domes to create definition through the skin (Fig.19). The thinner the skin the more the graft must integrate into the alar architecture and be highly beveled. The thicker the skin the more the graft projects above the domes and the sharper the edges (Fig. 19). The graft is sutured in place using 4-6 sutures of 5-0 Prolene.

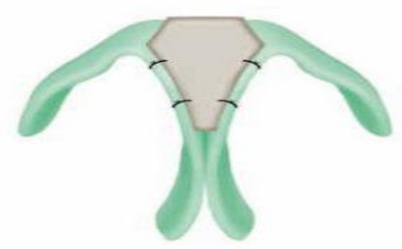

Fig.19: sculpturing of shield graft

\section{Sculpturing Spreader Grafts:}

The grafts are cut from the donor material using a \#11 blade. Thickness varies from the usual $1.5 \mathrm{~mm}$ up to $4 \mathrm{~mm}$ depending upon narrowness and asymmetry (Fig 20).
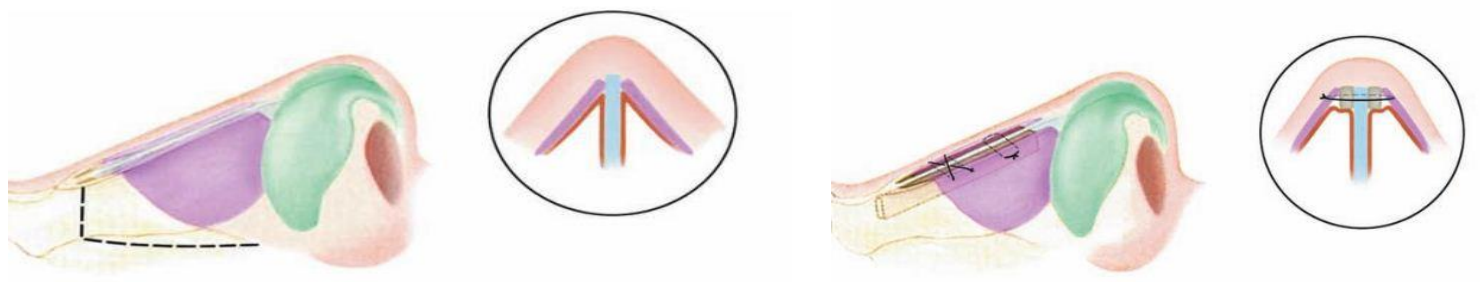
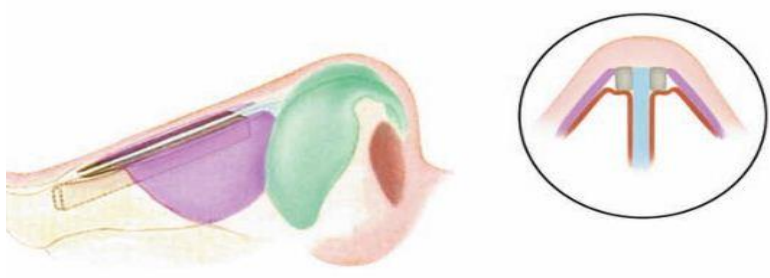
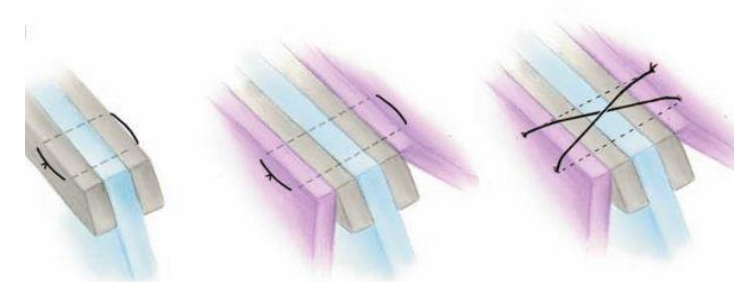

Fig.20: sculpturing spreader graft

Fig.21: fixation of spreader graft. 
The height is $2-3 \mathrm{~mm}$ to facilitate suturing and the length is $15-25 \mathrm{~mm}$ depending on availability. A true "pocket" as Sheen originally envisioned is not possible caudally in most cases but is very desirable cephalically, especially under the bony vault. The grafts are inserted one at a time making sure to have a smooth dorsum. They are held in place with two \#25 needles placed percutaneously through the skin. The needles pierce all five layers: the upper lateral

\section{Sculpturing Lateral Wall Grafts:}

A lateral wall graft is shaped like the upper lateral cartilage and then placed in a pocket directly over the upper lateral cartilage (ULC). To avoid visibility, the graft should be anatomically precise cartilage, then the spreader graft, the septum, spreader graft, and opposite upper lateral cartilage. The caudal end is sutured first with 5-0 Prolene often incorporating just the spreader grafts and the septum (three layers), whereas the cephalic suture incorporates the upper lateral cartilages as well (five layers). Suturing avoids accidental disruption or dorsal displacement (Fig.21). to correct a specific problem and placed in a pocket with suture fixation. The dorsal edge is precisely aligned with the dorsum. Full-length lateral wall grafts are not used as they tend to be visible ( Fig. 22).
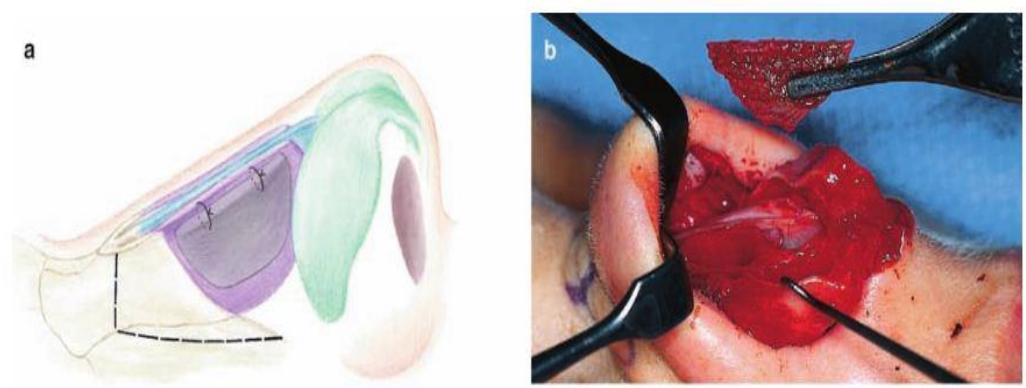

Fig. 22: sculpturing lateral wall graft.

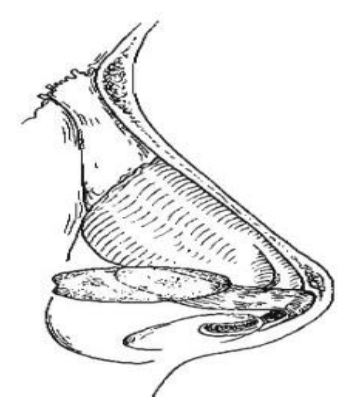

Fig.23: batten graft

\section{Sculpturing batten graft:}

The most common indication for an alar batten graft is external nasal valve collapse. Alar batten grafts, typically of curved septal or auricular cartilage, placed to support the alar rim, can correct internal or external nasal valve collapse (Fig.23).

Created a precise pocket for an alar batten, the graft is typically placed caudal to the lateral crura at the point of maximal lateral nasal wall collapse. Fashion a graft from harvested auricular or septal cartilage and insert it into the precise pocket. The pocket is subcutaneous and is placed at the point of maximal supra-alar collapse. Auricular cartilage is preferred because of the curvature of the cartilage. The convex side of the graft is oriented laterally to correct the supra alar pinching. If this pocket is too superficial, the graft may be palpable or visible. The graft is secured in place by sutures applied medially from the graft to adjacent soft or lateral crus.

\section{Sculpturing Cap graft:}

Typically, a tip graft should be projected $1 \mathrm{~mm}$. to $2 \mathrm{~mm}$. above the existing domes. In patients with thick skin and an under projected tip, a longer tip graft can be projected $2 \mathrm{~mm}$. to $4 \mathrm{~mm}$. above the existing dome. In these and other appropriate cases, a cap graft placed behind the leading edge of the tip graft may be useful to support the graft particularly softer, pliable auricular cartilage tip graft and to prevent excessive cephalic rotation of the graft under the tention of closure of the S.STE. Cap grafts are sutured to the tip graft and both domes by 


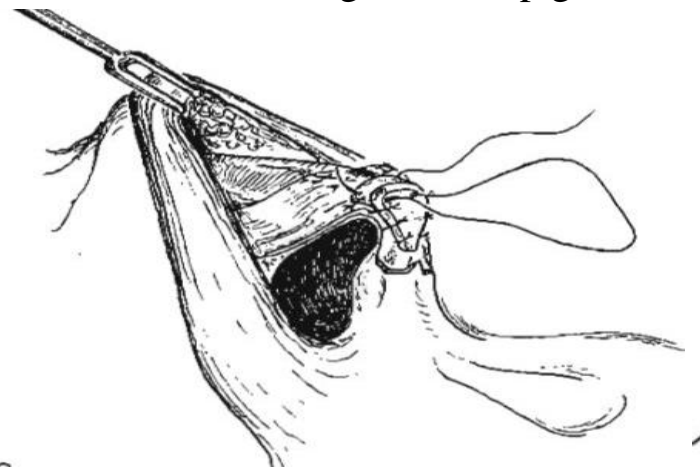

Fig.24: cap graft

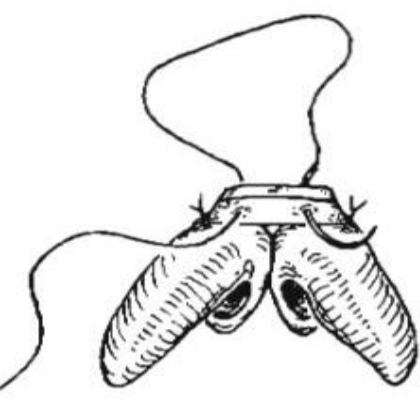

\section{Sculpturing dorsal onlay graft:}

The dorsal onlay grafts can be taken from various graft materials including septal cartilage and costal cartilage and bone. The graft varies in length, width and thickness according to the area of the dorsum to be augmented with. Sometimes a multi-layerd graft sutured together with 5-0 prolene is used whenever a bulk for augmentation is required (Fig.25).

\section{Postoperative care and follow up}

Most of cases were discharged the same or next date of surgery. They were prescribed alphintern caps (b.i.d) and bepanthen cream to be applied
Fig.25: dorsal on lay graft

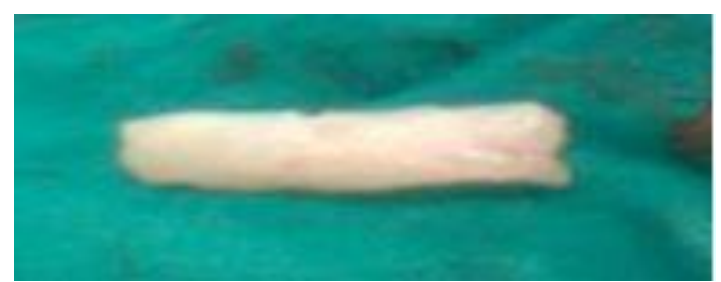

(t.i.d) locally to the stitches site, hydrogen peroxide solution to be applied locally to the prolene stitches to dissolve blood clots around it. Prolene stitches were removed by the $5^{\text {th }}$ day. External splint and sterristripe were removed by the $10^{\text {th }}$ day. The patient was photographed.

Follow up was performed on the day of stitch and splint removal, 6weeks and 4 months postoperatively. Evaluation of results was noticed, and complications were registered.

The following figure (Fig.26) demonstrated the method used to collect data. A tick mark $(\sqrt{ })$ was used to assign opposite the positive item. 


\begin{tabular}{|c|c|c|c|c|c|c|c|}
\hline Item & \# & $\%$ & Result & Item & \# & $\%$ & Result \\
\hline \multirow[t]{2}{*}{ Age } & & & \multirow{2}{*}{\begin{tabular}{|l|}
$18-25$ \\
$26-35$ \\
$36-45$ \\
\end{tabular}} & Septal deviation & & & $\begin{array}{l}\text { Yes } \\
\text { No }\end{array}$ \\
\hline & & & & \multirow{3}{*}{ Graft material } & & & \multirow{3}{*}{$\begin{array}{l}\text { Septal cartilage } \\
\text { Tragal cartilage } \\
\text { Conchal cartilage } \\
\text { Iliac crest bone } \\
\text { Trimmed LLC } \\
\text { Costal cartilage } \\
\end{array}$} \\
\hline Sex & & & \begin{tabular}{|l} 
Male \\
Female
\end{tabular} & & & & \\
\hline Residency & & & $\begin{array}{l}\text { Urban } \\
\text { Rural }\end{array}$ & & & & \\
\hline Socioeconomic state & & & \begin{tabular}{|l} 
Good \\
Low
\end{tabular} & \multirow[t]{4}{*}{ Graft type } & & & \multirow{4}{*}{\begin{tabular}{|l|} 
Columellar strut \\
Spreader graft \\
Shield graft \\
Dorsal onlay graft \\
Lateral onlay graft \\
Batten graft \\
Cap graft \\
plumping graft \\
Alar rim graft \\
Sept.ext. graft \\
L-shaped strut \\
Radix graft \\
\end{tabular}} \\
\hline Profession & & & \begin{tabular}{|l} 
White coated \\
Blue coated \\
House wife \\
Not working \\
Student \\
\end{tabular} & & & & \\
\hline Education & & & \begin{tabular}{|l|} 
Educated \\
Not educated
\end{tabular} & & & & \\
\hline Prior Rhinoplasty & & & \begin{tabular}{|l} 
Primary \\
Revision
\end{tabular} & & & & \\
\hline Aim of operation & & & $\begin{array}{l}\text { Functional } \\
\text { Aesthetic } \\
\text { Mixed }\end{array}$ & $\begin{array}{l}\text { Septoplasty } \\
\text { If yes, Indication }\end{array}$ & & & \multirow{3}{*}{\begin{tabular}{|l} 
Yes \\
No \\
Graft harvest \\
Nasal obstruction \\
Tension force release \\
Killian \\
Modified killian \\
Hemitransfixion \\
Complete transfixion
\end{tabular}} \\
\hline Motive for surgery & & & \begin{tabular}{|l} 
Self \\
Family \\
Colleges
\end{tabular} & \multirow{4}{*}{$\begin{array}{l}\text { Type of incision } \\
\text { Fig. of }(8) \text { closure } \\
\text { Nasal Pack } \\
\text { If Yes: Etiology }\end{array}$} & & & \\
\hline Skin Quality & & & $\begin{array}{l}\text { Good } \\
\text { Very Thick }\end{array}$ & & & & \\
\hline Cartilage Quality & & & \begin{tabular}{|l|} 
Strong \\
Week
\end{tabular} & & & & $\begin{array}{l}\text { Yes } \\
\text { No } \\
\text { Yes }\end{array}$ \\
\hline Deformity no./case & & & $\begin{array}{l}\text { Single deformity } \\
\text { Multiple deformity }\end{array}$ & & & & \begin{tabular}{|l} 
No \\
Bleeding control \\
Framework support
\end{tabular} \\
\hline \multirow[t]{2}{*}{ Deformity type } & & & \multirow{2}{*}{$\begin{array}{l}\text { Crocked nose } \\
\text { Hump nose } \\
\text { Alar rim retraction } \\
\text { Bulbous tip } \\
\text { Tip ptosis } \\
\text { Tip deviation } \\
\text { Flaring alae } \\
\text { Nasal valve collapse } \\
\text { Saddle nose }\end{array}$} & Overall results: & & & \begin{tabular}{|l} 
Fully corrected \\
Partially corrected
\end{tabular} \\
\hline & & & & Complications & & & \begin{tabular}{|l} 
Infection \\
Graft displacement \\
Visible graft \\
Irregularity \\
Scarring \\
Bleeding \\
Graft rejection \\
\end{tabular} \\
\hline Nasal Trauma & & & $\begin{array}{l}\text { Yes } \\
\text { No }\end{array}$ & Patient satisfaction & & & \begin{tabular}{|l} 
Satisfied \\
Unsatisfied
\end{tabular} \\
\hline
\end{tabular}

Fig.26: illustrates Table of Data collection (empty).

\section{CASES PRESENTATION}

Case 1: Case\#14 Deformity: supratip saddling, deviated tip \& caudal septal deviation.

Grafts: dorsal onlay graft of tragal cartilage, shield graft and cap graft.

A 32years old female presented with nasal obstruction (LT side mainly), saddle nose and big nasal tip. She gave history of nasal trauma 6years ago. Examination and analysis: revealed supratip saddling, trapezoid deviated tip and caudal septal deviation to the right side

Operative technique: \#Dorsal approach septoplasty and total septal reconstruction, Part of it 
was cut as a graft. The remaining straight part was interposed between medial crura and extended cephalically to lie between upper lateral cartilages it was fixed by 5-0 prolene mattress sutures cephalically with the upper lateral cartilages and caudally with the medial crura.\#Humpectomy by rasping. \#Lateral running spanning

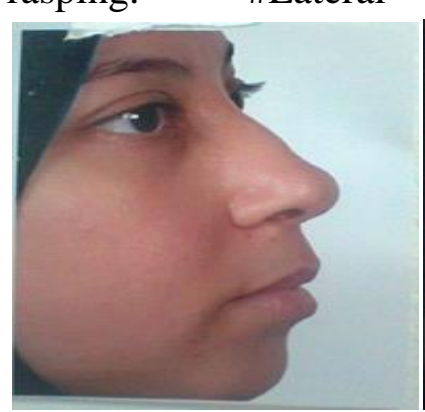

Before Lateral Fig.27

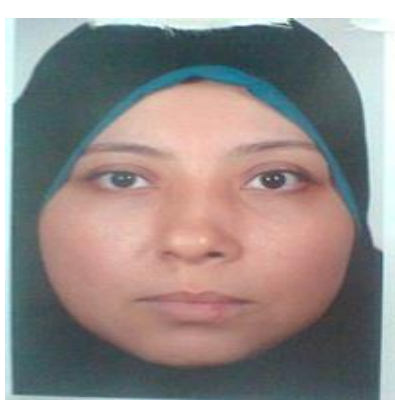

Before Frontal Fig.31

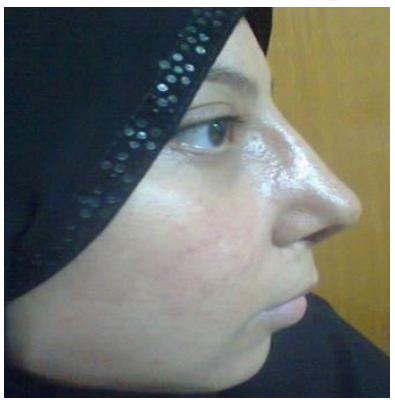

AfterFig,28

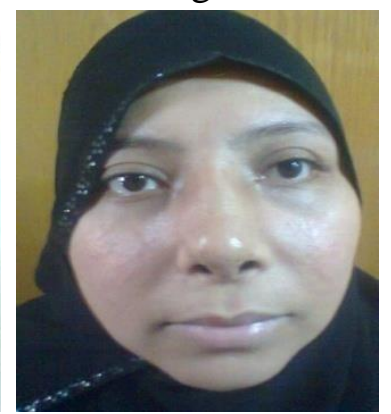

After Fig.32:

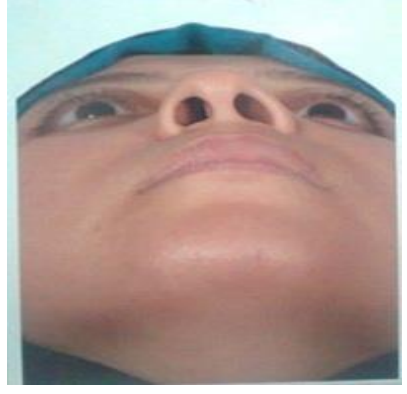

Before Basal Fig.29

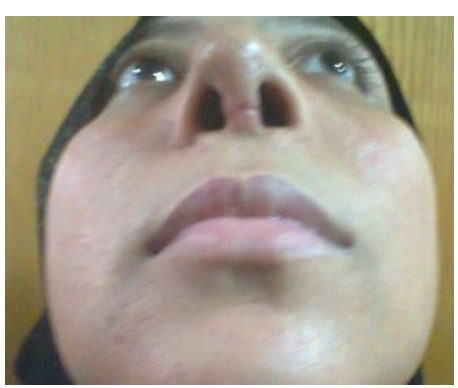

After Fig.30
Case 2 Case\# 15: Deformity: Severe saddle nose, low radix, low dorsum.

Grafts: Multi layered dorsal onlay graft,left lateral crural batten graft and shield graft.

17 years old male presented with nasal deformity and nasal obstruction happened after sever blunt nasal trauma. Examination and analysis Revealed low dorsum, low radix, huge supratip saddling, divergent lateral wall of RT nasal bone and depressed lateral wall of left nasal bone. The deformity was mainly in the middle one third.
sutures\#Transdomal and interdomal sutures.\#Septal cartilage graft was insufficient and tragal cartilage graft was harvested bilaterally. \#Application of a multi layered dorsal onlay graft. \#Application and fixation of shield graft. \#Application and fixation of cap 


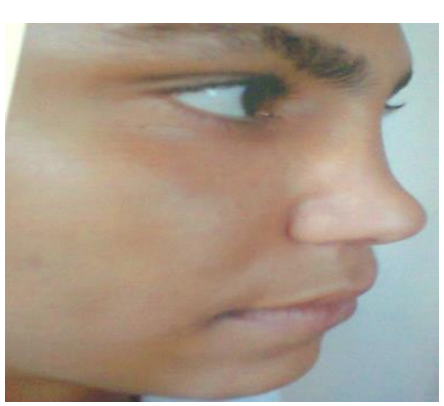

Before: Fig.33 Lateal view After Fig.34

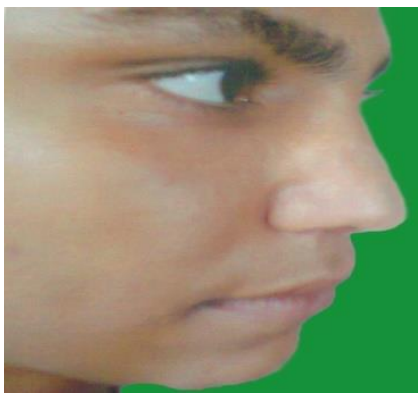

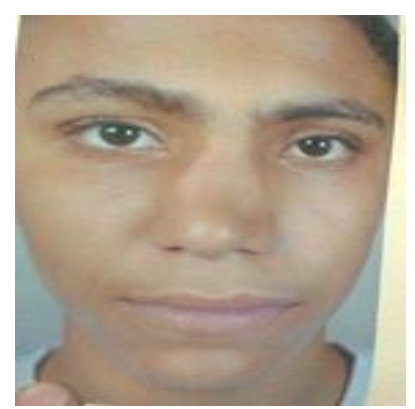

Before Frontal Fig.35

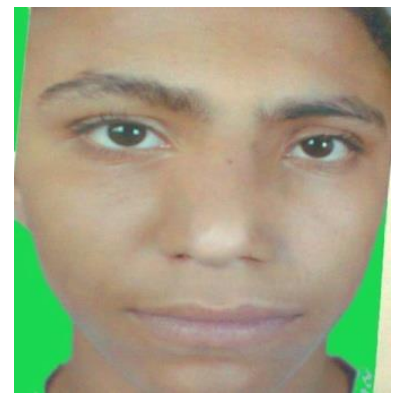

After Fig.36

\section{Case 3 Case \#11}

Deformity: Moderate saddle nose.

Graft: Unilateral spreader graft, dorsal onlay graft, bilateral lateral onlay grafts \& alar batten graft.

A 21 years old male presented with nasal deformity and nasal obstruction. He gave history of sever blunt trauma 5 years ago.

Examination and analysis revealed moderate saddle nose, bulbous tip, alar flaring and tilted nasal septum to the left side.

\section{Operative technique:}

\#Open technique. \#Dorsal approach septoplasty by separation of medial crurae and dissection onto anterior septal angle. \#Septal cartilage graft harvest. \#Application and fixation of a right side spreader
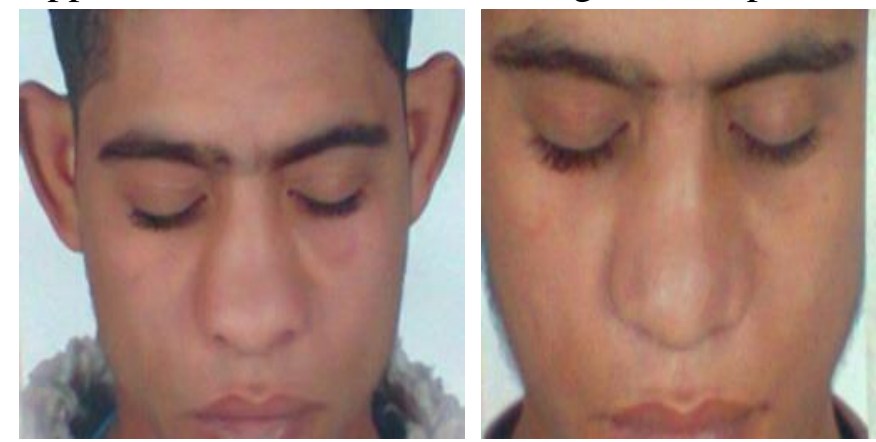

Fig.37 Frontal view(Before) Fig.38 (After)
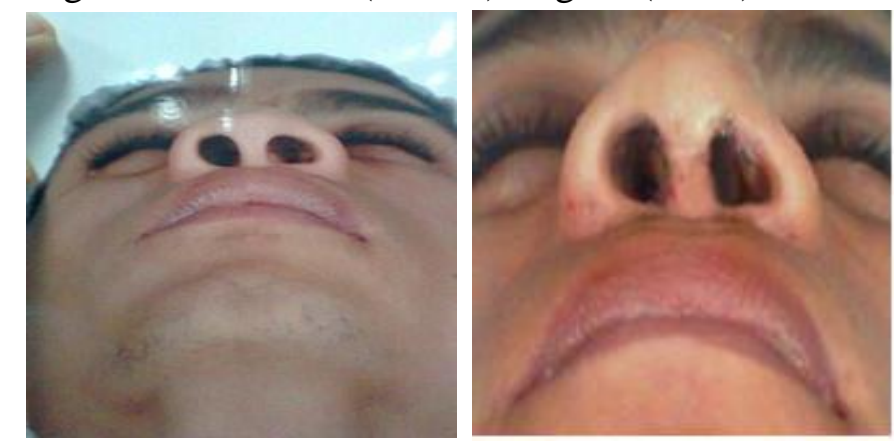

Fig.41: Basal view(before) Fig.42(after)

graft to straighten the tilted septum and to supply a base for the dorsal onlay graft to be applied. \#Application of dorsal onlay graft to the middle 1/3 of the dorsum to bridge saddling. \#Application of lateral wall onlay graft bilaterally to correct lateral wall depression. \#Application of a right alar batten onlay graft to overcome asymmetry of the lower one third of the nose. \#Transdomal/interdomal sutures to refine the tip and increase tip projection. \#Application and fixation of extended columellar strut to enforce tip support, increase tip projection, reduce alar flaring and correct asymmetry of the nasal base. \# Bilateral alar base wedge resection to reduce residual flaring.

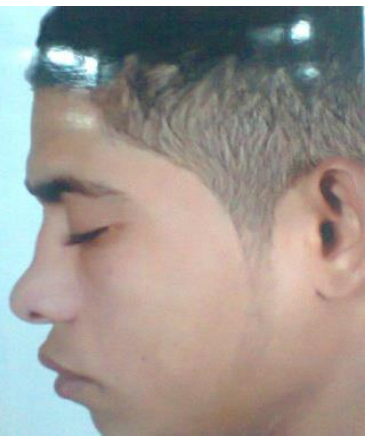

Fig.39 Lateral (before)

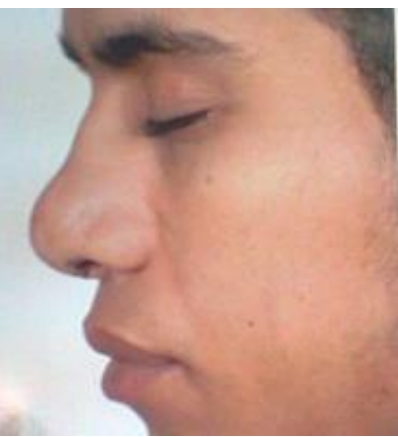

Fig.40 (after) 
Case 4 Case\# 1: Deformity: crocked nose lower $1 / 3$, tip deviation, tip ptosis and wide alar base.

Graft type: L-shaped columellar strut.

A 25 years old male presented with deviated tip to the right, tip ptosis and wide alar base. He had open rhinoplasty operation 18 months before revision operation to correct nasal deformity and obstruction. Obsruction was corrected by septoplasty, spurectomy and bilateral inferior turbinate bipolar diathermy. Tip ptosis and flaring were corrected by columellar strut to enforce tip support and increase tip projection. Tip Deviation
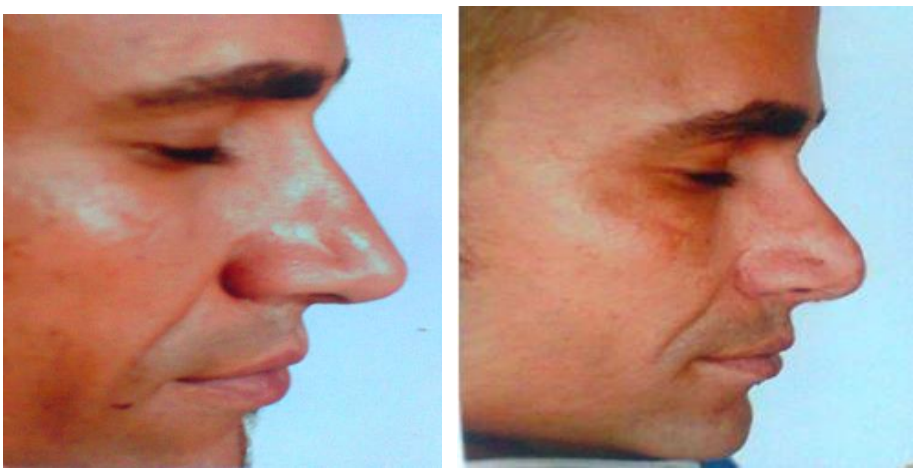

Fig.43: Lateral view (before) Fig.44 (after)
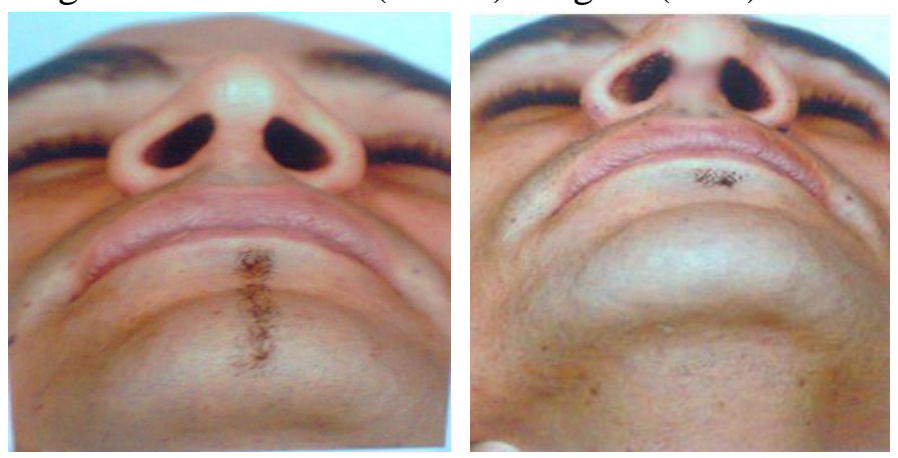

Fig.47: basal view (before) Fig.48 (after)

Case 5: Deformity: crocked nose, asymmetric dropped tip, C-shaped septal deviation and caudal dislocation Graft: septal extention graft, shield graft and lataral crural batten graft.

21 years old male presented with deviated long nose and nasal obstruction. History of nasal trauma 3 years ago.

Examination and analysis Revealed dveiated nasal dorsum to the right side, asymmetric dropped nasal tip, C-shaped septal deviation. The caudal end of the was camouflaged by a left lateral crural overlay graft, but aesthetic outcome was unsatisfactory.

\section{Operative technique:}

\# Revision open technique \#Dorsal approach septoplasty by dissection inbetween the lower lateral cartilages onto anterior septal angle.The remained septal cartilage found was insufficient as a graft material. \# Costal cartilage graft was harvested from the right $6^{\text {th }}$ rib. \# L-shaped strut was carved from the excised costal cartilage was applied and fixed, to enforce tip support, increase tip projection, and correct deviation. \# Bilateral wedge resection of alar base to reduce residual flaring.
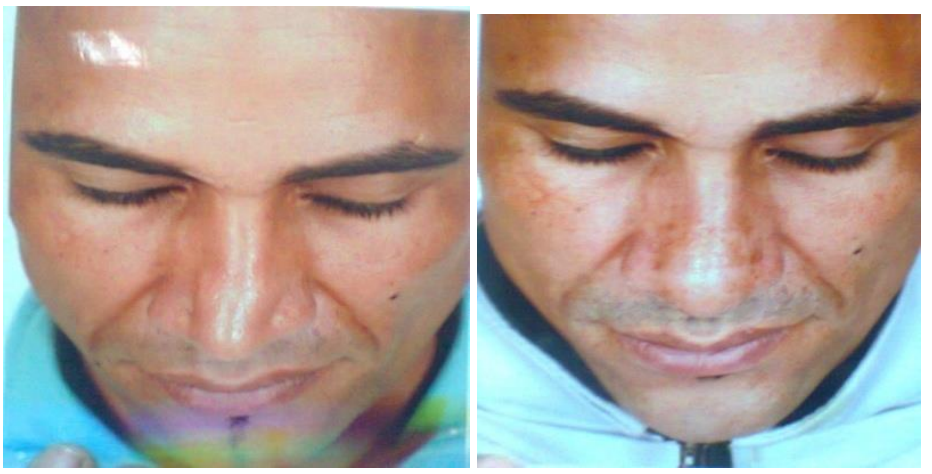

Fig.45: frontal view( before) Fig.46 (after) septum was pushed to the left nostril, asymmetric nostrils and nasal hump.

\section{Surgical technique:}

\# Dorsal approach septoplasty by dissection and separation in-between medial crurae of the L.L.Cs. to reach anterior septal angle and flaps elevation. Septum was found deflected to the right side and the caudal septum was curved and its end was bent to the left. The deviated caudal part was resected to affect straightening the caudal sepum, and shorten 
the nose. \# Septal cartilage graft harvest. \# humpectomy with osteotome which led to open roof dorsum.\# Lateral crural overlay technique to shortening the nose \& rotate the tip. \#Transdomal / interdomal sutures to affect tip definition and refinement. \#Application and fixation of septal extension graft to affect straightening the nasal septum and increase tip support \# Medial crural
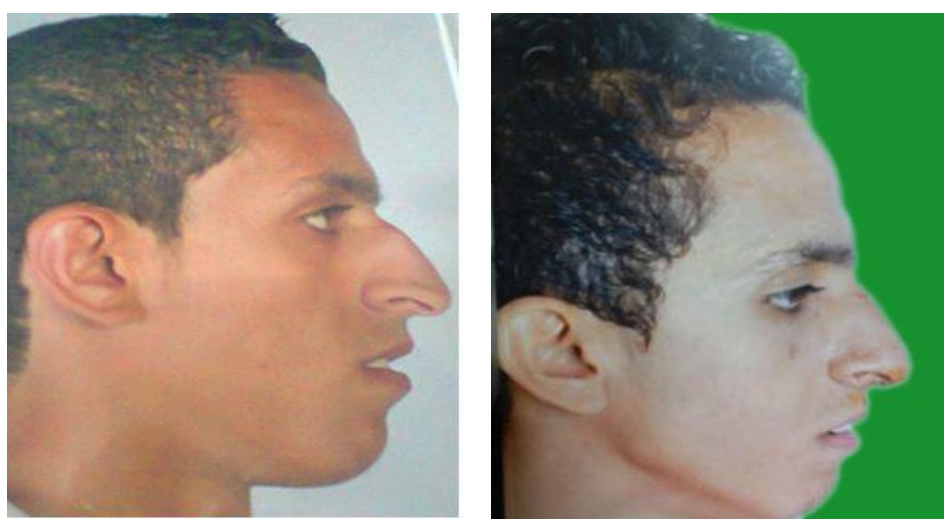

Fig.49: Lateral view( Before)

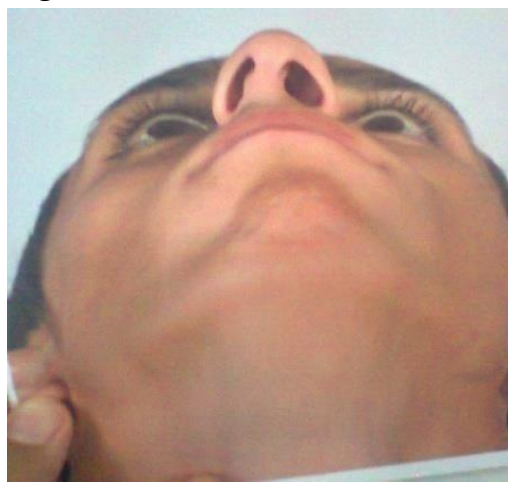

Fig.53: Basal view (before)
Fig.50 (after)

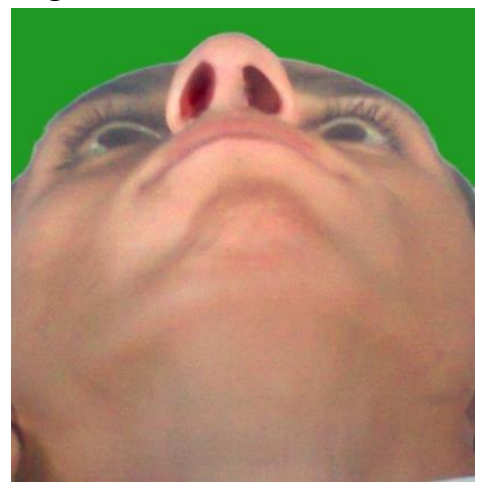

Fig54 (after) sutures to increase tip support, tip projection, tip rotation and to supply a base for shield graft application. \#Application and fixation of Shield graft to affect tip definition, rotation, projection and to correct asymmetric tip.

\#Application of left alar batten graft to camouflage residual deviation. \# Lateral osteotomies to close open roof, closure of incisions and splint.

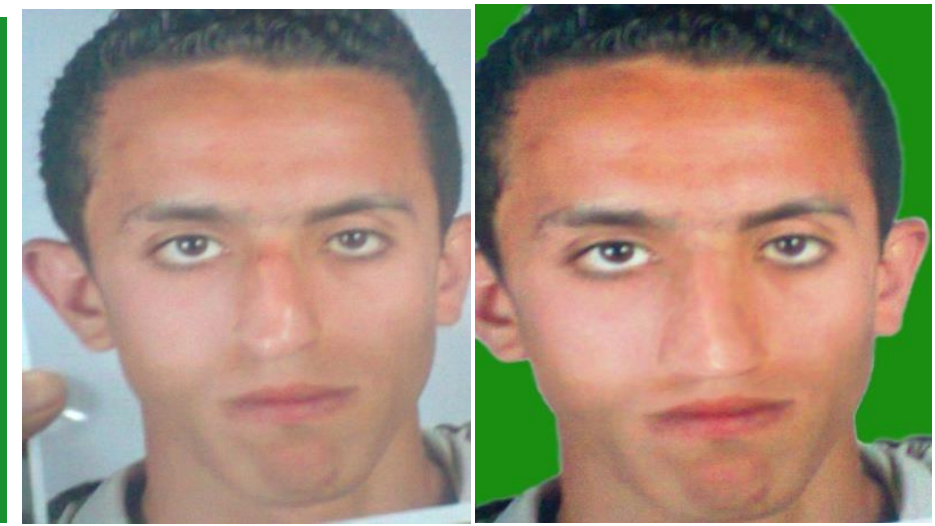

Fig.51: Frontal view(before) Fig.52 ( after)
Case 6 Case \# 5: Deformity: crocked nose, Cshaped deviation, deviated septum and caudal septal dislocation.

onlay graft.

Graft: columellar strut, lateral

17 years old male presented with a crocked nose and nasal obstruction. There was history of nasal trauma 10 years ago.Examination and analysis: revealed crocked nose with $\mathrm{C}$-shaped deformity, a deviated nasal septum with anterior septal dislocation, nasal hump (mainly bony), bulbous tip and generally big nose.

\section{Operative technique:}

\# Open technique. \# Septoplasty via killian incision with complete release of tension forces to help straightening of deviated cartilages and resection of the severely curved part of the septum which will be used as a graft material. \# Humpectomy by rasping \# Medial and lateral osteotomies to affect straightening of the deviated bone. \# Cephalic trimming of the lower lateral cartilages to reduce bulk of the lower $1 / 3$ of the nose. \# Transdomal /interdomal sutures to affect tip refinement and increase tip projection. \# Application of standard columellar strut to increase tip support and increase tip projection. \# Application of a right lateral onlay graft to camouflage residual deviation. \# Double 
mattress sutures applied to the dorsal part of septum to fix it with the upper lateral cartilages to prevent saddling. \# A bluish discoloration of the tip skin which was managed by application of warm saline fomentation.

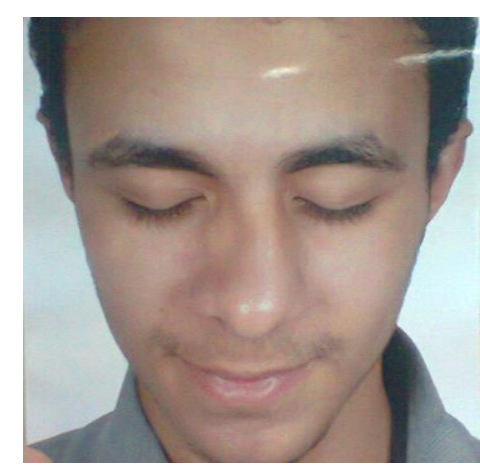

Fig.55: Frontal view (before) Fig.56 (after)
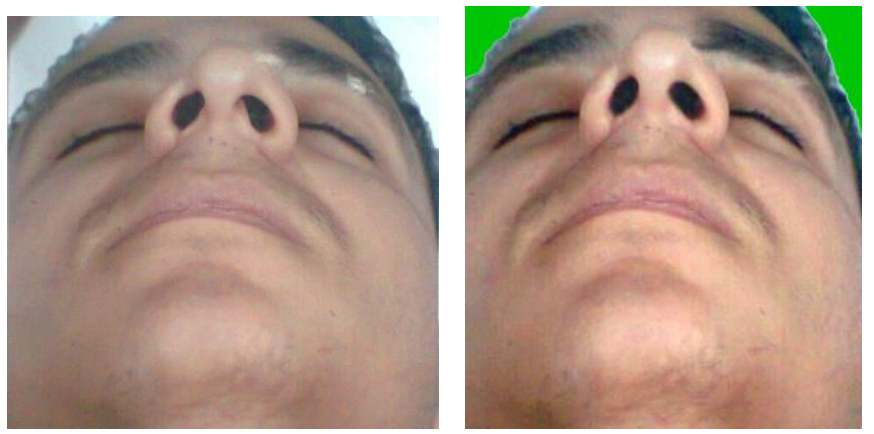

Fig.59: Basal view ( before)

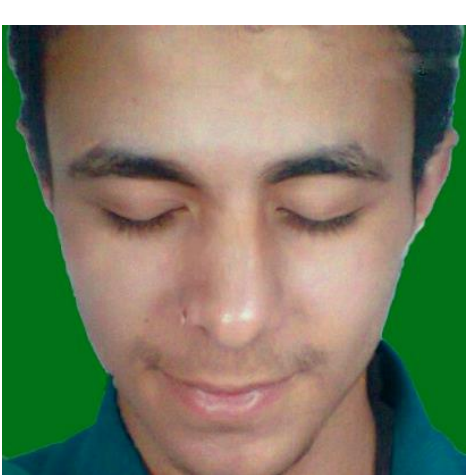

Fig.60 (after)

Case 7 Case\#10: Deformity: Tip ptosis, and septal perforation.

Graft: Extended columellar strut, shield graft.

A 23 years old male presented with nasal deformity and obstruction. He gave history of nasal trauma followed by nasal obstruction and hyposmia. 3 years later he underwent septoplasty and turbinectomy after which he got a septal perforation.Examination and analysis Showed anterior medium sized septal perforation, dropped tip with loss of tip support.

\section{Operative technique:}

\#Septum was perforated and septal cartilage was deficient. \#Tragal cartilage graft harvested from the RT side. \#Left hemitransfixion incision, dissection

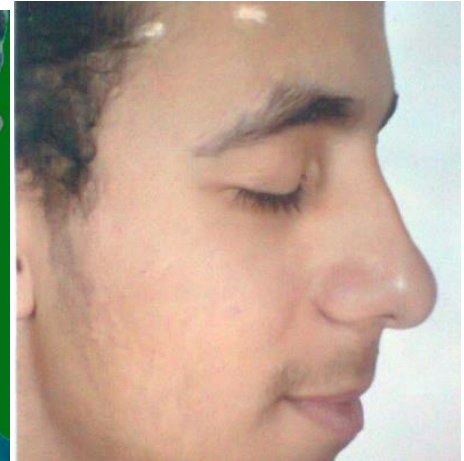

Fig.57: Lateral view

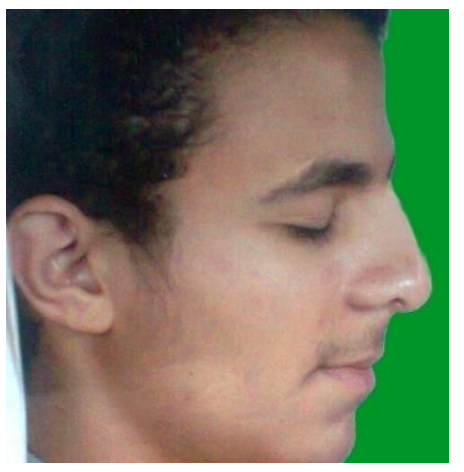

Fig.58 (after) of mucopeichondrial flap from all around septal perforation. \#Insertion of a piece of tragal cartilage inbetween flaps at the site of perforation to close the perforation in the way that it reached the dorsum of the septum and fixed with $4 / 0$ vicryl. \#Advancement of the mucoperichondrial flap by a release incision caudally to allow closure of the perforation. \#Closure of hemitransfixion incision by 4/0vicryl and the mucoperichondrial flap was secured with figure of (8) 4/0 vicryl sutures. \#Open approach. \#Application and fixation of extended columellar to support, project and rotate the tip. \#Application and fixation of a shield graft to define and more project and rotate the tip. \#Closuer of incisions and application of sterristripe. \#Application of external nasal splint. 


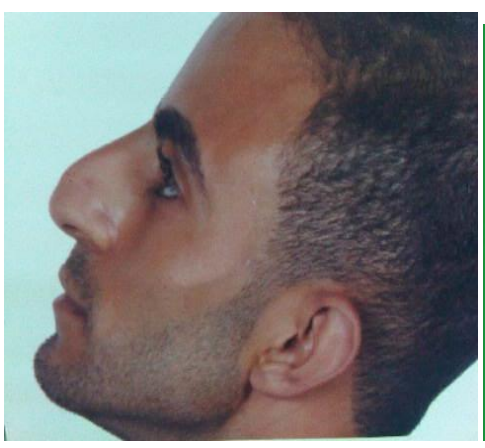

Fig.61 lateral view( beore)

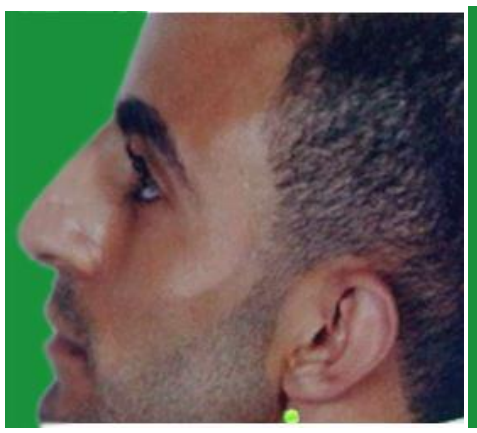

Fig.62 (after)

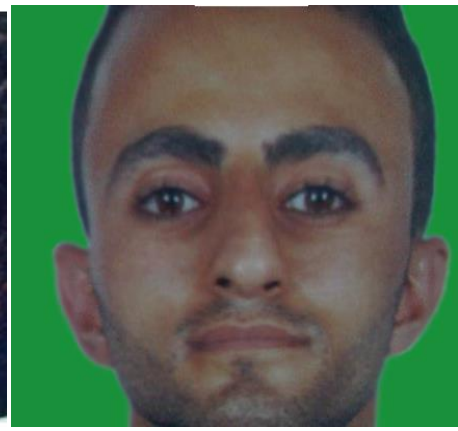

Fig.63 frontal view(before) Fig.64(after)
Case 8: Deformity: tip ptosis, septal deviation and hump nose.

Graft: Septal extension graft, Shield graft and dorsal onlay graft.

18 years old male patient, presented with dropped tip, nasal hump and nasal obstruction. Examination and analysis: Showed, tip ptosis and c-shaped septal deviation which caused right sided nasal obstruction and osteocartilagenous hump.

\section{Operative technique:}

\#Dorsal approach septoplasty by dissection inbetween medial crurae to reach anterior septal angle and total septal reconstruction by cutting off the deviated part of the septal cartilage, cris-cross scoring of the removed cartilage, removal of the high maxillary crest, repositioning of the treated cartilage in the opposite direction of deviation as a septal extension graft and fixation in place with the mucoprichondrial flap by figure of 8 5-0 vicryl sutures. \#Cephalic trimming of the lower lateral cartilages. \#Transdomal /interdomal sutures with 50 prolene. \#Humpectomy with powered drill then shaving of the cartilage with scalpel. \#Medial and lateral osteotomies to close the open roof. \#Application and fixation of columellar strut to enforce, project and rotate the tip. \#Application and fixation of shield graft to rotate, project and definand support tip.

\# Cutting off the depressor septi nasi muscle to resolve the tension upper lip through upper buccal sulcus transverse incision then verticalclosure of incision with 5-0 vicryl.

N.B.: on dorsal palpation,saddling was discovered and corrected by dorsal onlay graft.

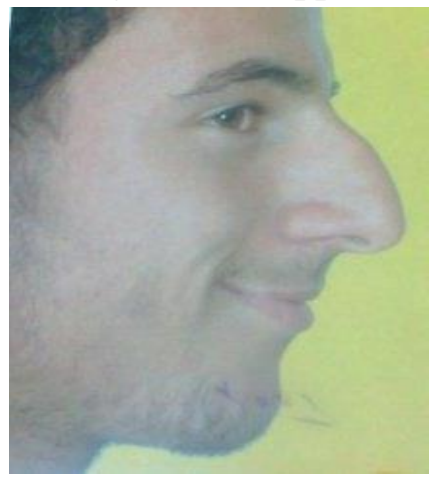

Fig.65: Lateral view(before) Fig,66 (after)

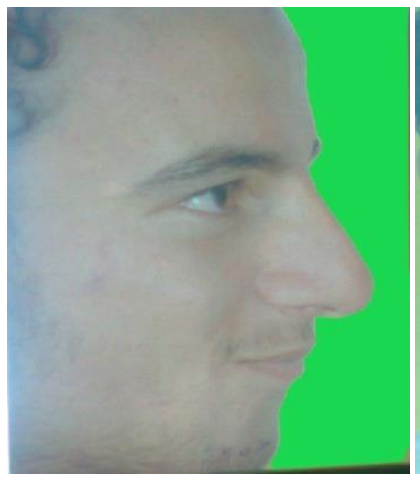

Case \# 9: Deformity: Bilateral Alar rim retraction

Graft: Bilateral alar rim batten grafts. 34 years oold male presented with exagerated columellar show, bilateral alar rim retraction associated with nasal hump.

\section{Operative technique:}

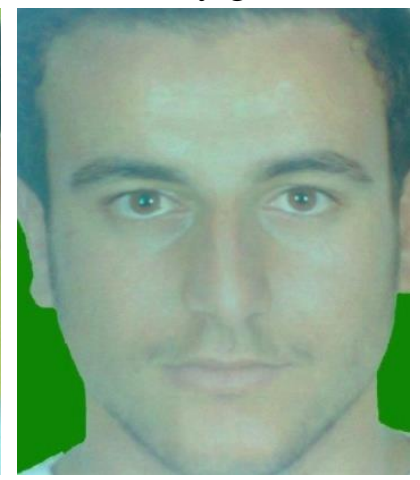

Fig.68(after)

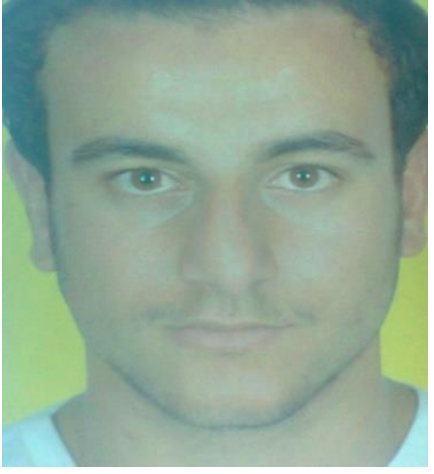

Fig.67: frontal view
\# Open technique. \# Septoplasty via left killian incision to harvest septal cartilage graft. \# Humpectomy by rasping. \# Application and fixation of onlay alar rim batten graft bilaterally to correct alar rim retraction \# 

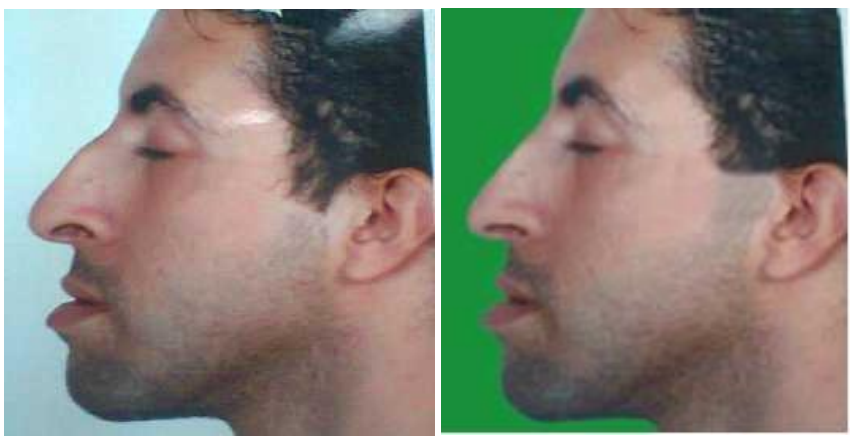

Fig.69 Lateral view (before) Fig.70 (after)

Case 10: Deformity: Wide base, ill suppored deprojected tip and septal deviation.

Graft: Columellar strut and lateral crural onlay graft.

A 24 years old male presented with nasal obstruction and nasal deformity. Examination and analysis: showed deviated nasal septum to the Lt side. Septal spur, hypertrophied inferior turbinates bilaterally, dropped deviated tip and wide alar base.

\section{Operative technique:}

\#Septoplasty via left killian incison \#Removal of inferior part of quadrilateral cartilage. \#Direct

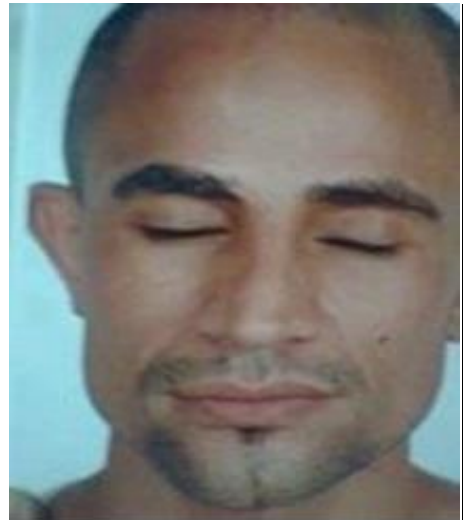

Fig73: frontal View(before)

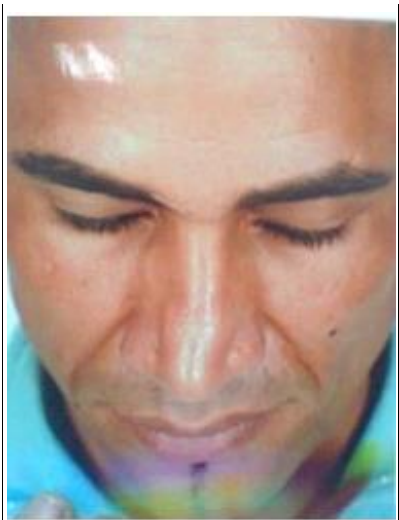

Fig74 (after
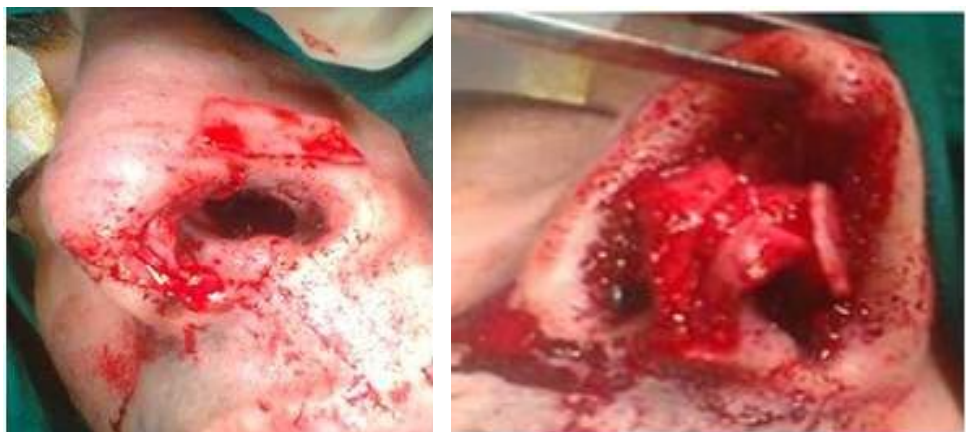

Fig.71: alar batten graft simulated Fig72 graft fixed( Left) posteranterior incision over septal spur and dissection of mucopeioasteom bilaterally and spurrectomy. \#Submucous diathermy of nferor turbinates bilaterally \#Open approach rhinoplasty \#Dissection of S-STE out of nasal framework \#Cephalic trimming of LLC bilaterally \#Lateral running spanning sutures \#Transdomal/ interdomal sutures \#Application and fixation of columellar strut (Fig. to project and support the tip and to decrease alar flaring. \#Deviation of tip was found and camouflaged with left lateral crural onlay graft \#Closure of incisions \#Application of sterristripe \#Application of internal nasal silicon splint

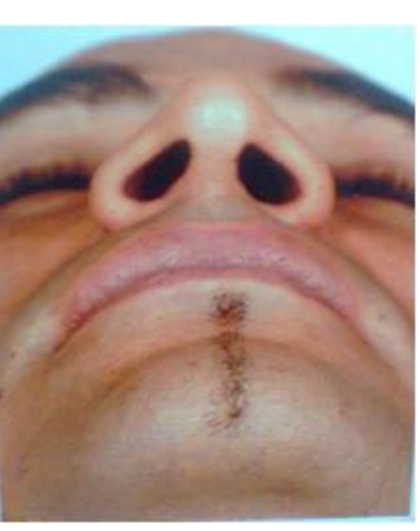

Fig75 Basal view (before)

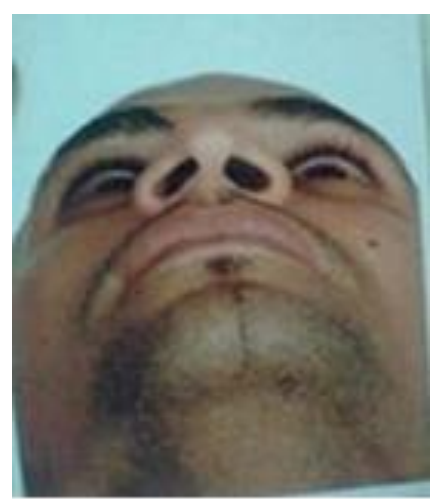

Fig76 (after) 


\section{RESULTS}

(Fig.30) illustrates table of cases data representation (filled). 35 patients operated by the open technique, 23 were males while 12 were females. Of them, 32 cases were fully corrected while, 3 cases were partially corrected. Complications were minimal, occurred in 3 cases. The majority of cases (32 cases) were satisfied while 3 cases were unsatisfied.
These deformities included were 9 cases $(25.7 \%)$ crocked nose, 12 cases ( $34.3 \%$ ) had flaring base, 12 cases (34.3\%)nasal tip ptosis, 9 cases (25.7\%) saddle nose, 1 case $(2.86 \%)$ had short nose, 12 cases (34.3\%) had bulbous tip, 19 cases (54.3\%) had nasal hump and one case $(2.86 \%)$ had internal nasal valve collapse (Table \&chart15).

\begin{tabular}{|c|c|c|c|c|c|c|c|}
\hline Item & $\#$ & $\%$ & Result & Item & $\#$ & $\%$ & Result \\
\hline \multirow[t]{2}{*}{ Age } & \multirow{2}{*}{\begin{tabular}{|l|}
21 \\
7 \\
7 \\
\end{tabular}} & \multirow{2}{*}{$\begin{array}{l}60 \\
20 \\
20 \\
\end{array}$} & \multirow{2}{*}{$\begin{array}{l}18-25 \\
26-35 \\
36-45 \\
\end{array}$} & Septal deviation & $\begin{array}{l}14 \\
21\end{array}$ & $\begin{array}{l}40 \\
60\end{array}$ & $\begin{array}{l}\text { Yes } \\
\text { No }\end{array}$ \\
\hline & & & & \multirow{3}{*}{ Graft material } & \multirow{3}{*}{\begin{tabular}{|l|}
28 \\
3 \\
2 \\
1 \\
1 \\
1
\end{tabular}} & \multirow{3}{*}{$\begin{array}{l}80 \\
8.6 \\
5.7 \\
2.85 \\
2.85 \\
2.85 \\
\end{array}$} & \multirow{3}{*}{$\begin{array}{l}\text { Septal cartilage } \\
\text { Tragal cartilage } \\
\text { Conchal cartilage } \\
\text { Iliac crest bone } \\
\text { Trimmed LLC } \\
\text { Costal cartilage }\end{array}$} \\
\hline Sex & $\begin{array}{l}23 \\
12\end{array}$ & $\begin{array}{l}65.7 \\
34.3\end{array}$ & $\begin{array}{l}\text { Male } \\
\text { Female }\end{array}$ & & & & \\
\hline Residency & \begin{tabular}{|l|}
25 \\
10
\end{tabular} & $\begin{array}{l}71.4 \\
29.6\end{array}$ & $\begin{array}{l}\text { Urban } \\
\text { Rural }\end{array}$ & & & & \\
\hline Socioeconomic state & \begin{tabular}{|l|}
25 \\
10
\end{tabular} & $\begin{array}{l}71.4 \\
28.6\end{array}$ & $\begin{array}{l}\text { Good } \\
\text { Low }\end{array}$ & \multirow[t]{4}{*}{ Graft type } & \multirow{4}{*}{\begin{tabular}{|l|}
20 \\
5 \\
11 \\
16 \\
2 \\
4 \\
5 \\
1 \\
2 \\
2 \\
3 \\
1
\end{tabular}} & \multirow{4}{*}{\begin{tabular}{|l|}
57.14 \\
14.28 \\
31.42 \\
45.71 \\
5.7 \\
11,4 \\
14.3 \\
2.6 \\
5.7 \\
2.6 \\
8.57 \\
2.6
\end{tabular}} & \multirow{4}{*}{$\begin{array}{l}\text { Columellar strut } \\
\text { Spreader graft } \\
\text { Shield graft } \\
\text { Dorsal onlay graft } \\
\text { Lateral onlay graft } \\
\text { Batten graft } \\
\text { Cap graft } \\
\text { plumping graft } \\
\text { Alar rim graft } \\
\text { Sept.ext. graft } \\
\text { L-shaped strut } \\
\text { Radix graft }\end{array}$} \\
\hline Profession & \begin{tabular}{|l|}
12 \\
5 \\
4 \\
3 \\
11 \\
\end{tabular} & \begin{tabular}{|l|}
34.3 \\
14.3 \\
11.4 \\
8.6 \\
31.4 \\
\end{tabular} & $\begin{array}{l}\text { White coated } \\
\text { Blue coated } \\
\text { House wife } \\
\text { Not working } \\
\text { Student }\end{array}$ & & & & \\
\hline Education & \begin{tabular}{|l|}
32 \\
3 \\
\end{tabular} & $\begin{array}{l}91.4 \\
8.6\end{array}$ & $\begin{array}{l}\text { Educated } \\
\text { Not educated }\end{array}$ & & & & \\
\hline Prior Rhinoplasty & \begin{tabular}{|l|}
33 \\
2
\end{tabular} & \begin{tabular}{|l|}
94.28 \\
5.72 \\
\end{tabular} & $\begin{array}{l}\text { Primary } \\
\text { Revision }\end{array}$ & & & & \\
\hline Aim of operation & \begin{tabular}{|l|}
1 \\
18 \\
16 \\
\end{tabular} & \begin{tabular}{|c|}
2.9 \\
51.4 \\
45.7 \\
\end{tabular} & $\begin{array}{l}\text { Functional } \\
\text { Aesthetic } \\
\text { Mixed } \\
\end{array}$ & \multirow[t]{3}{*}{$\begin{array}{l}\text { Septoplasty } \\
\text { If yes, Indication }\end{array}$} & \multirow{3}{*}{$\begin{array}{l}30 \\
5 \\
27 \\
14 \\
11 \\
15 \\
3 \\
7 \\
1\end{array}$} & \multirow{3}{*}{\begin{tabular}{|l|}
85.7 \\
14.3 \\
77.4 \\
40 \\
31.4 \\
40 \\
8.6 \\
20 \\
2.85
\end{tabular}} & \multirow{3}{*}{\begin{tabular}{|l|} 
Yes \\
No \\
Graft harvest \\
Nasal obstruction \\
Tension force release \\
Killian \\
Modified killian \\
Hemitransfixion \\
Complete transfixion
\end{tabular}} \\
\hline Motive for surgery & \begin{tabular}{|l|}
24 \\
5 \\
6 \\
\end{tabular} & \begin{tabular}{|l|}
68.57 \\
14.28 \\
17.15 \\
\end{tabular} & $\begin{array}{l}\text { Self } \\
\text { Family } \\
\text { Colleges }\end{array}$ & & & & \\
\hline Skin Quality & \begin{tabular}{|l|}
19 \\
16
\end{tabular} & \begin{tabular}{|l|}
54.28 \\
45.72 \\
\end{tabular} & \begin{tabular}{|l|} 
Good \\
Very Thick
\end{tabular} & & & & \\
\hline Cartilage Quality & \begin{tabular}{l|}
24 \\
11 \\
\end{tabular} & \begin{tabular}{|l|}
68.6 \\
31.4 \\
\end{tabular} & \begin{tabular}{|l|} 
Strong \\
Week
\end{tabular} & \multirow{2}{*}{$\begin{array}{l}\text { Fig. of }(8) \text { closure } \\
\text { Nasal Pack } \\
\text { If Yes: Etiology }\end{array}$} & $\begin{array}{l}25 \\
10 \\
3\end{array}$ & \multirow{2}{*}{$\begin{array}{l}71.4 \\
28.6 \\
8.5 \\
91.4 \\
2.6 \\
5.7\end{array}$} & \multirow{2}{*}{$\begin{array}{l}\text { Yes } \\
\text { No } \\
\text { Yes } \\
\text { No } \\
\text { Bleeding control } \\
\text { Framework support }\end{array}$} \\
\hline Deformity no./case & $\begin{array}{l}2 \\
33\end{array}$ & $\begin{array}{l}5.7 \\
94.3\end{array}$ & $\begin{array}{l}\text { Single deformity } \\
\text { Multiple deformity }\end{array}$ & & $\begin{array}{l}32 \\
1 \\
2\end{array}$ & & \\
\hline \multirow[t]{2}{*}{ Deformity type } & \multirow{2}{*}{\begin{tabular}{|l|}
9 \\
19 \\
1 \\
12 \\
12 \\
8 \\
12 \\
1 \\
9 \\
\end{tabular}} & \multirow{2}{*}{\begin{tabular}{|c|}
25.7 \\
54.3 \\
2.86 \\
34.3 \\
34.3 \\
22.8 \\
34.3 \\
2.86 \\
25.7 \\
\end{tabular}} & \multirow{2}{*}{$\begin{array}{l}\text { Crocked nose } \\
\text { Hump nose } \\
\text { Alar rim retraction } \\
\text { Bulbous tip } \\
\text { Tip ptosis } \\
\text { Tip deviation } \\
\text { Flaring alae } \\
\text { Nasal valve collapse } \\
\text { Saddle nose }\end{array}$} & Overall results: & $\begin{array}{l}32 \\
3 \\
\end{array}$ & $\begin{array}{l}91.4 \\
8.6 \\
\end{array}$ & $\begin{array}{l}\text { Fully corrected } \\
\text { Partially corrected }\end{array}$ \\
\hline & & & & Complications & $\begin{array}{l}1 \\
0 \\
1 \\
0 \\
0 \\
1 \\
0\end{array}$ & \begin{tabular}{|l|}
2.85 \\
0 \\
2.85 \\
0 \\
0 \\
2.85 \\
0 \\
\end{tabular} & $\begin{array}{l}\text { Infection } \\
\text { Graft displacement } \\
\text { Visible graft } \\
\text { Irregularity } \\
\text { Scarring } \\
\text { Bleeding } \\
\text { Graft rejection } \\
\end{array}$ \\
\hline Nasal Trauma & $\begin{array}{l}20 \\
15\end{array}$ & \begin{tabular}{|l|}
57.14 \\
42.86
\end{tabular} & $\begin{array}{l}\text { Yes } \\
\text { No }\end{array}$ & Patient satisfaction & $\begin{array}{l}32 \\
3\end{array}$ & \begin{tabular}{|l|}
91.4 \\
8.6
\end{tabular} & $\begin{array}{l}\text { Satisfied } \\
\text { Unsatisfied }\end{array}$ \\
\hline
\end{tabular}


Fig.77: Table of Data representation (filled).

\begin{tabular}{|l|l|c|c|}
\hline Item & Data Group & $\#$ & $\%$ \\
\hline \multirow{4}{*}{$\begin{array}{l}\text { Deformity } \\
\text { type }\end{array}$} & Crocked nose & 9 & 25.7 \\
\cline { 2 - 4 } & Hump nose & 19 & 54.3 \\
\cline { 2 - 4 } & $\begin{array}{l}\text { Alar rim } \\
\text { retraction }\end{array}$ & 1 & 2.86 \\
\cline { 2 - 4 } & tip Bulbous & 12 & 34.3 \\
\cline { 2 - 4 } & Tip ptosis & 12 & 34.3 \\
\cline { 2 - 4 } & Tip deviation & $\mathbf{8}$ & $\mathbf{2 2 . 8}$ \\
\cline { 2 - 4 } & Flaring alae & 12 & 34.3 \\
\cline { 2 - 4 } & $\begin{array}{l}\text { Nasal valve } \\
\text { collapse ( } \\
\text { internal) }\end{array}$ & 1 & 2.86 \\
\cline { 2 - 4 } & Saddle nose & 9 & 25.7 \\
\hline
\end{tabular}

Table 1.

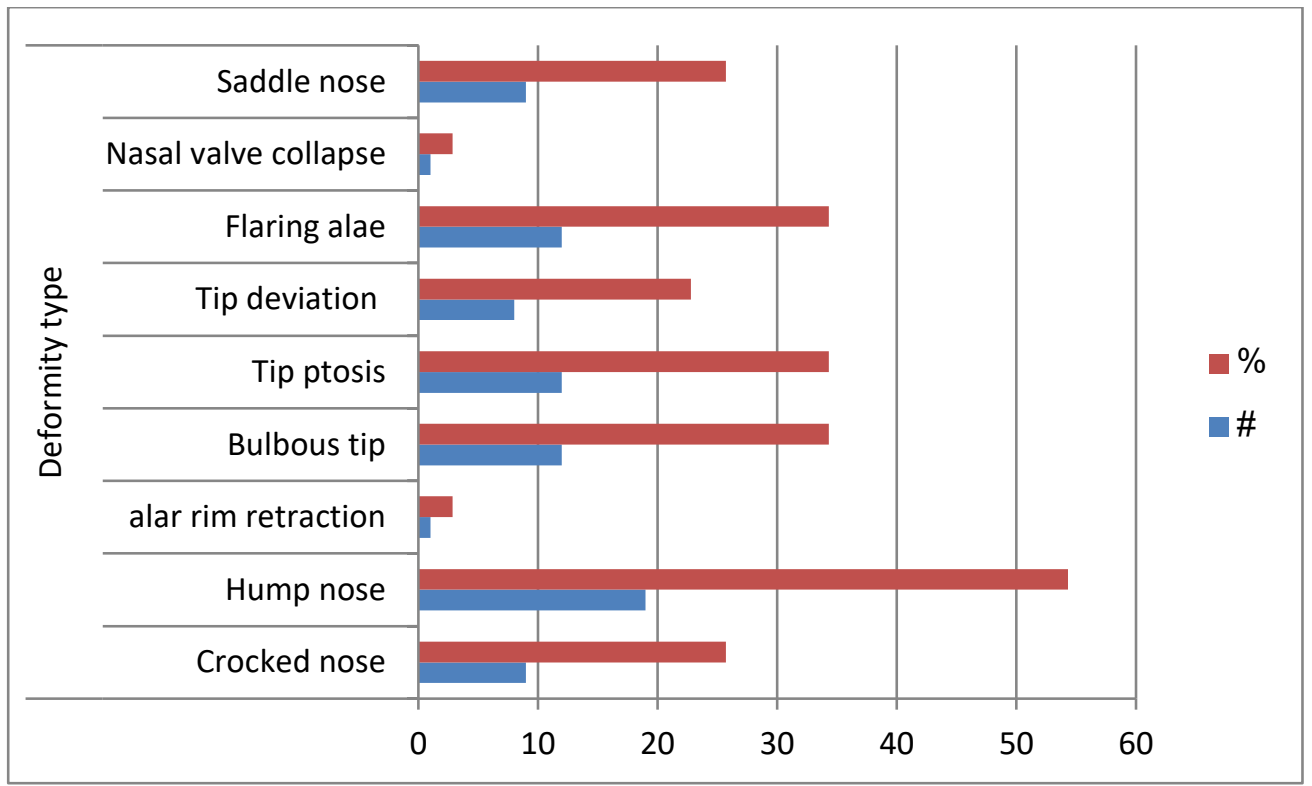

\section{Chart 1.}

With regard to the graft material and source, the most commonly used material was septal cartilage which was applied in 28 cases $(80 \%), 3$ cases

\begin{tabular}{|l|l|c|c|}
\hline Item & Data Group & $\#$ & $\%$ \\
\hline \multirow{3}{*}{$\begin{array}{l}\text { Graft } \\
\text { material }\end{array}$} & Septal cartilage & 28 & $\mathbf{8 0}$ \\
\cline { 2 - 4 } & Tragal cartilage & $\mathbf{3}$ & $\mathbf{8 . 6}$ \\
\cline { 2 - 4 } & Conchal cartilage & $\mathbf{2}$ & $\mathbf{5 . 7}$ \\
\hline \multirow{7}{*}{} & & & \\
\cline { 2 - 4 } & Iliac crest bone & 1 & 2.8 \\
\cline { 2 - 4 } & Trimmed LLC & 1 & 2.8 \\
\cline { 2 - 4 } & Costal cartilage & 1 & 2.8 \\
\hline
\end{tabular}

Table 2.
(8.6\%) with Tragal cartilage, 2 cases (5.7\%) with conchal cartilage, one case

(2.8\%) with iliac bone crest and another one case (2.8\%) with trimmed LLC (Table \&chart16). 


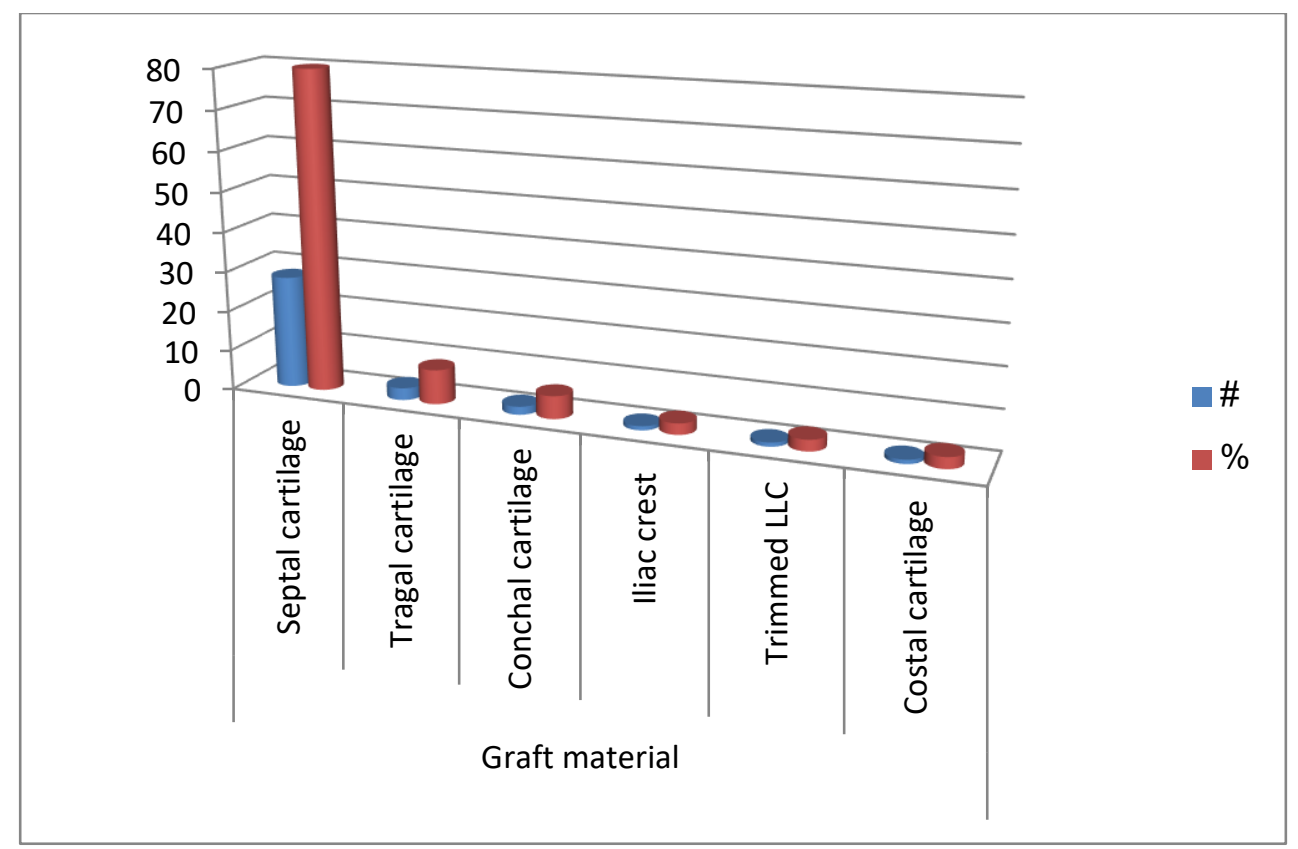

\section{Chart 2.}

The utilized grafting techniques were as follows: Columellar strut applied in 20 cases ( $57.1 \%$ ), 16 cases $(45.7 \%)$ dorsal onlay grafts, 11 cases $(31.4 \%)$ shield grafts, 5 cases $(14.3 \%)$ cap grafts, 4cases $(11.4 \%)$ batten grafts, 5 cases $(14.3 \%)$ spreader grafts, 2cases $(5.7 \%)$ rim alar eim graft, one case $(2.7 \%)$ septal extention graft and one case $(2.7 \%$ ) corrected with L-shaped strut dorsal graft ( Table \& Chart 17).

\begin{tabular}{|l|l|c|c|}
\hline Item & Data group & $\#$ & $\%$ \\
\hline Graft type & Columellar strut & 20 & 57.1 \\
\cline { 2 - 4 } & Spreader graft & 5 & 14.3 \\
\cline { 2 - 4 } & Shield graft & 11 & 31.4 \\
\cline { 2 - 4 } & Dorsal onlay graft & 16 & 45.7 \\
\cline { 2 - 4 } & Lateral onlay graft & 2 & 5.7 \\
\cline { 2 - 4 } & Batten graft & 4 & 11.4 \\
\cline { 2 - 4 } & Cap graft & 5 & 14.3 \\
\cline { 2 - 4 } & Alar rim graft & 1 & 5.7 \\
\cline { 2 - 4 } & Sept.ext. graft & 3 & 2.6 \\
\cline { 2 - 4 } & L-hsaped strut & 1 & 2.57 \\
\cline { 2 - 4 } & Radix graft & 1 & 2.6 \\
\cline { 2 - 4 } & Plumbing graft & & \\
\hline
\end{tabular}

Table 3. 


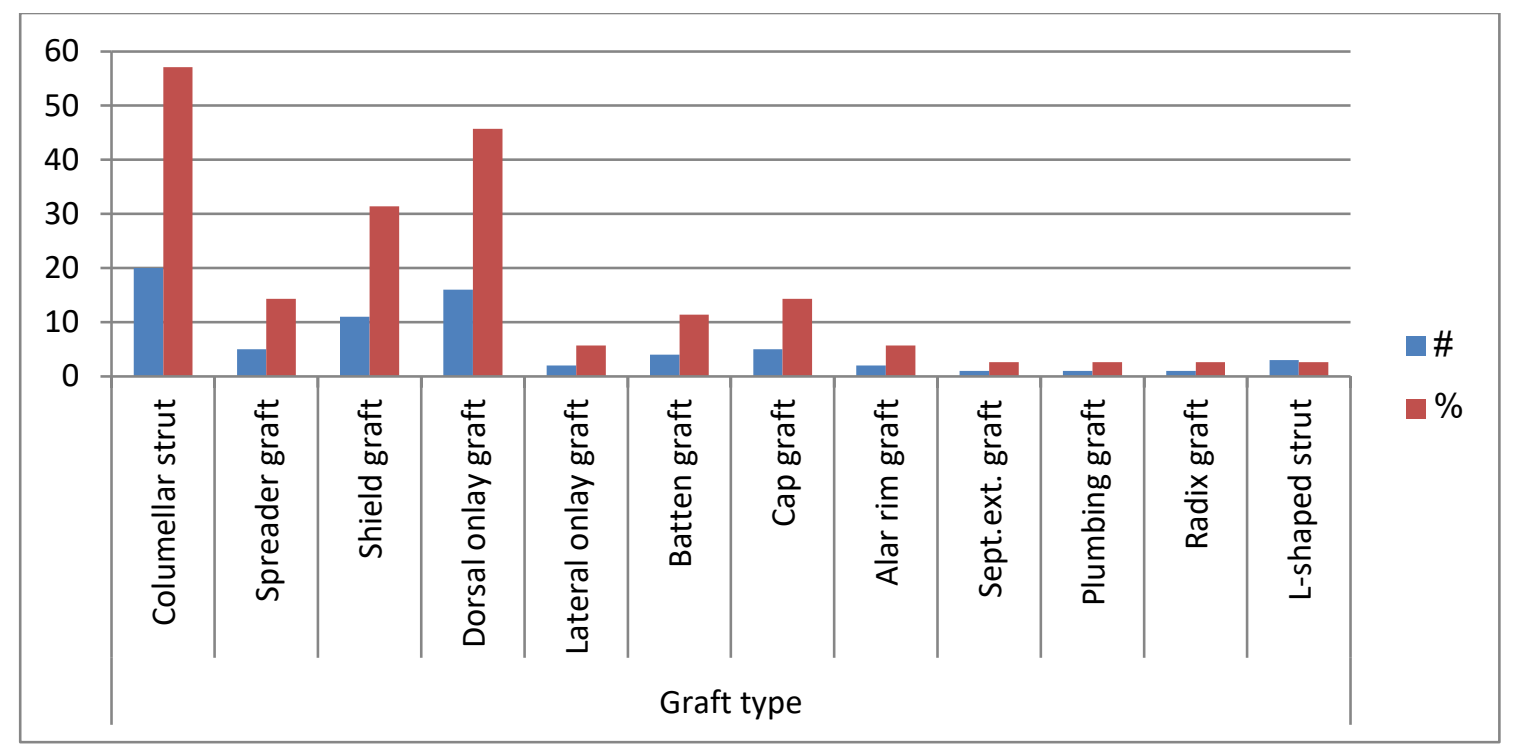

Chart 3

Discussion

The aim of a successful rhinoplasty is to establish good esthetic results while preserving satisfactory nasal function

In this thesis, the most common graft material used was septal cartilage which was applied in 28 cases (80\%), 3 cases (8.6\%) with Tragal cartilage, 2 cases (5.7\%) with conchal cartilage, one case (2.8\%) with iliac crest bone and one case (2.8\%) with trimmed LLC (Table \&Chart15).

Different grafting techniques were utilized in the present study (Table \& Chart 16).

A variety of graft materials including autologous, homologous and alloplastic materials are used in nasal surgery. Autologous cartilage, especially septal cartilage is considered as the ideal graft material due to its long term stability, low complication rates, low donor site morbidity and high biocompatibility (Tardy et al., 1985).

When septal cartilage is not available due to nasal trauma or previous nasal surgery, auricular (conchal \& tragal), costal cartilage or iliac crest

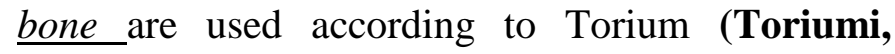
2000).

In cases with minor augmentation requirements, materials that are harvested from nose (turbinate bone, maxillary crest, trimmed lower lateral cartilage) or auricular cartilage which has lower donor site morbidity compared to costal cartilage are preferred according to Mischkowski and coworkers (Mischkowski et al., 2008).

In this work, costal cartilage was used in one case of saddle nose and tip ptosis as L- shaped strut graft follow up of the case did not meet such a complication

Although, costal cartilage, costochondral graft and bone grafts are frequently used in the nasal augmentation, most preferable is costal cartilage. problems related to surgical morbidity, physical shape, physiological adaptation and resorbtion were reported with the use of costal cartilage $n$ a study conducted by Gurley et al. 2001 (Gurley et al., 2001).

In this work, homologous or alloplastic graft materials were not used

Homogenous implants are not widely accepted due to patient refusal and pronounced resorbtion rates in a study performed by Hwang K et al. 2007 (Hwang et al., 2007).

A variety of alloplastic materials are available, however, complications such as foreign body reactions, infection, instability, extrusion are reported at varying ratios with these implants (Peled et al., 2008) In this study, open rhinoplasty 
technique was utilized. Open approach gave good functional results and corrected most of the deformities of the external nose along with any severity of septal deviation was also corrected; 32 cases $(\mathbf{9 1 . 4 \% )}$ were fully corrected while, 3 cases (8.6\%) were partially corrected (Table \&Chart. 3). The primary advantage of the external rhinoplasty technique is exposure, while its main fear concern is the columellar scar and postoperative nasal tip edema. The results of this thesis did not encounter such a complication. In a study conducted by Shafaqat Islam et al, (Shafaqat Islam et al, 2016); a close result to this study was found. Regarding Complications, the present thesis showed minimal complications, occurred in 3 cases $(8.6 \%)$, one of them $(2.85 \%)$ was tip skin infection occurred after one week post operatively and was resolved with antibiotics. The second case $(2.85 \%)$ was visible graft due to a thin skin envelop and the third case $(2.85 \%)$ was post-operative nasal bleeding controlled with nasal tampon (Table \&chart 4).

\section{Conclusion \& Summary}

Clinical judgment remains the most important determinant in selecting the appropriate type, size, and shape of graft used to correct nasal deformities. Each material offers advantages that may be necessary based on the clinical scenario and nature of the required effect. Similarly, each graft may have disadvantages that preclude its use in different cases. It is important for the surgeon to be aware of such advantages and disadvantages and the appropriate indications and techniques needed to overcome some of the limitations of the grafting method so that the optimal aesthetic and reconstructive result is achieved

\section{REFERENCES}

1-Garrison FH: An Introduction to the History of Medicine. Philadelphia: WB Saunders, 1917: 60-62.
2-Gurley JM, Pilgram T, Perlyn CA, Marsh JL: Long-term outcome of autogenous rib graft nasal reconstruction. Plast Reconstr Surg. 2001; 108:1895-1905.

\section{3-Hwang K, Hwang JH, Park JH, Kim DJ, Shin} $\boldsymbol{Y H}$ : Experimental study of autologous cartilage, acellular cadaveric dermis, lyophilized bovine pericardium, and irradiated bovine tendon: applicability to nasal tip plasty. J Craniofac Surg. 2007; 18:5518.

4-Masters FW, Manchester GH: A history of aesthetic rhinoplasty. In: Masters FW, Lewis JR, eds. Symposium on Aeschelic Surgery of the Nose, Ears and Chin. Saint Louis: CV Mosby, 1973: 3-7.

5-McDowell F, Valone J A, Brown JE (1952): Bibliography and historical note on plastic surgery of the nose. Plast. Reconstr. Surg; 10: 149-185.

6-Mischkowski RA, Domingos-Hadamitzky C, Siessegger M, Zinser MJ, Zöller JE.: Donor site morbidity of ear cartilage autografts. Plast reconstr surg. 2008; 121:79-87.

7-Peled ZM, Warren AG, Johnston P, Yaremchuk MJ.: The use of alloplastic materials in rhinoplasty surgery: a meta-analysis. Plast reconstr Surg. 2008; $121: 85$ e-92e.

8-Shafqat Islam, Aamir Yousuf: A comparative analysis of Rhinoplasty open vs endonasal approach-Our experience. Imperial Journal of interdisciplinary Research (IJIR) Vol-2, Issue-2; 386-392, 2016.

9-Sheen JH (1987): Aesthetic rhinoplasty, 2nd ed. CV Mosby Co., St. Louis 99.

10-Tardy ME, Denny J, Fritsch MH: The versatile cartilage autograft in reconstruction of the nose and face. Laryngoscope 95:523-533, 1985. 